\title{
Mass spectrometry of alkylbenzenes and related compounds. Part II. Gas phase ion chemistry of protonated alkylbenzenes (alkylbenzenium ions)
}

\author{
Dietmar Kuck \\ Universität Bielefeld, Fakultät für Chemie, Postfach 8640, D-4800 Bielefeld 1, Federal Republic of \\ Germany
}

\section{INTRODUCTION}

Mass spectrometry and ion chemistry of alkylbenzenes, today, is much more than the gas-phase reactions of their radical cations and their prominent fragment ions, such as $\mathrm{C}_{7} \mathrm{H}_{7}{ }^{+}$and $\mathrm{C}_{7} \mathrm{H}_{8}{ }^{+}$. Indeed, the gas-phase chemistry of gaseous ions originating mainly from the electron impact (EI) ionization of alkylbenzenes has been investigated extensively for more than 35 years and has revealed to us numerous amazing insights in elementary chemical processes. Many of these aspects, covered in Part I of this review (1), are under continuous investigation.

Nevertheless, this has been only half of the story. Mass spectrometry of alkylbenzenes also comprises the gas-phase chemistry of protonated alkylbenzenes. Interest in protonated alkylbenzenes developed with the introduction of chemical ionization (CI) mass spectrometry (2-6). Munson and Field (7) were the first to apply this method to alkylbenzenes. However, the much closer relevance of evenelectron, protonated arene ions to electrophilic aromatic substitution $(8,9)$ in solution and synthetic organic chemistry in general has made the gas-phase ion chemistry of protonated alkylbenzenes an independently important topic of mass spectrometric research. At the same time it was found that protonated alkylbenzenes can be generated in superacidic media (10) and studied by nuclear magnetic resonance spectrometry as well as by other spectroscopic techniques (11-17). Furthermore, computational approaches were widely applied to estimate the intrinsic properties of these ions (18).

Later, besides simple protonation, ion-molecule reactions were used to generate transient or collisionally stabilized adduct ions from electrophiles and aromatic substrates. In additions to CI mass spectrometry, newer and complementary techniques were applied, among them, ion cyclotron resonance [ICR (19-21)] and high-pressure chemical ionization mass spectrometry [HPCI, (22)], triple-stage quadrupole mass spectrometry [TQMS (23)], and radiolytic and nuclear fission 
experiments (24-26). By now, a vast knowledge on gas-phase chemistry of protonated alkylbenzenes has developed.

No review on gaseous protonated benzenes and alkylbenzenes and related species has appeared up to now. Some articles offer a collection of special, mainly thermochemical and kinetic aspects (27-29). The most recent compendium (30) on the thermochemical properties of gaseous ions contains numerous data on protonated arenes. By contrast, exhaustive treatments describe the chemistry of arenes in acidic and superacidic solutions (11-17). It appears that the interconnections between solution and gas-phase arenium ion chemistry are more fruitful than recognized by many 'liquid-phase' organic chemists. A very notable treatment combining gas-phase and solution chemistry of organic ions appeared in 1985 (31). In fact, mass spectrometry is a powerful complementary tool to our knowledge and understanding of elemental chemical processes of organic species.

This review discusses the chemistry of gaseous protonated alkylbenzenes from the viewpoint of organic chemistry and stresses the variety of ways in which these ions occur in mass spectrometry and related fields. As a conceptual link with the chemistry presented in Part I, it will be shown first that protonated benzene and alkylbenzenes are also very commonly formed in the conventional EI source, both by isomerization and by apparently simple fragmentation. Examples will demonstrate that EI-induced fragmentation of suitably "tailored" organic compounds may give rise to comfortably high abundances of protonated alkylbenzenes, offering a valuable independent access to these species.

\section{FORMATION OF BENZENIUM AND ALKYLBENZENIUM IONS IN MASS SPECTROMETRY}

In parallel to Part I of this review, we first collect the evidence for the occurrence of benzenium-type ions under the conditions of EI mass spectrometry. The formation of protonated alkylbenzenes under $\mathrm{CI}$ conditions and during ion-molecule reactions in related gas-phase experiments, including radiolysis and nuclear fission, will be discussed subsequently.

\section{A. Alkylbenzenium ions from radical cations}

Although not strictly proven in every case, protonated arenes are very frequently formed from radical cationic precursors. The most prominent examples are $\mathrm{C}_{6} \mathrm{H}_{7}{ }^{+}(1)$ and $\mathrm{C}_{7} \mathrm{H}_{9}{ }^{+}(2$, Scheme 1), which form the uppermost signals of the peak triplets at $m / z 77-79$ and $m / z$ 91-93 in the EI mass spectra of alkylbenzenes and related compounds (32). The formation of ions 1 and 2 has been suggested in classical articles and textbooks on organic mass spectrometry (33). In fact, loss of $\mathrm{H}^{*}$ and $\mathrm{H}_{2}$ are straightforward fragmentation paths of these ions (Section III). While most of these benzenium ions arise from intramolecular rearrangement processes, there are few examples for a straightforward, EI-induced simple-cleavage reaction leading directly to benzenium and alkylbenzenium ions-notably without "external" protonation. 


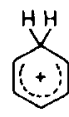

1

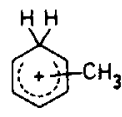

2

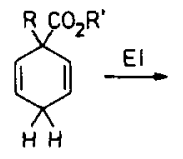

3

$\mathrm{R}=\mathrm{H}$, alkyl; $\mathrm{R}^{\prime}=\mathrm{H}, \mathrm{CH}_{3}$

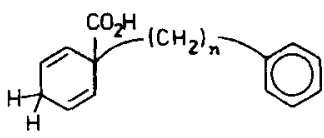

6

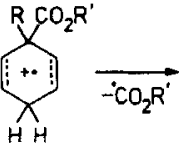

6

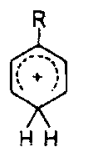

5

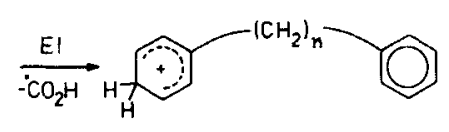

7

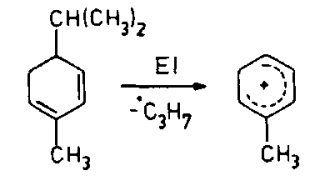

8

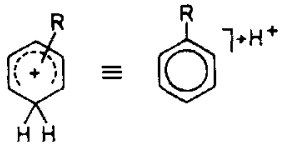

Scheme 1

\section{Fragmentation by simple cleavage}

Cyclohexadienes and their derivatives exhibit strong peaks for the corresponding $[\mathrm{M}-\mathrm{H}]^{+}$and $[\mathrm{M}-\mathrm{R}]^{+}$ions. In the case of dihydrobenzoic acids and their methyl esters (3), the molecular ions (4) are particularly fragile and yield very abundant $\left[\mathrm{M}-\mathrm{CO}_{2} \mathrm{R}\right]^{+}$or $\left[\mathrm{M}-\mathrm{CO}_{2} \mathrm{CH}_{3}\right]^{+}$ions (Scheme 1). This approach was first utilized by Kuck et al. (34) to generate regiospecifically "protonated" $\alpha, \omega-$ diphenylalkanes [( $\omega$-phenylalkyl)benzenium ions] 7 from 6 and was then extended to a variety of arenium ions (35-42), including mononuclear ones such as benzenium, toluenium (31), xylenium, and ethylbenzenium ions $(41,42)$. As a general experience, the isomerization and fragmentation reactions of the EI-generated (alkyl)benzenium ions are exactly the same as those produced independently by protonation of the corresponding alkylbenzenes.

It may be mentioned that the dihydroarene approach has some parallel to the preparation of alkylbenzenium salts from halocyclohexadienes in solution (43). Instead of the dihydrobenzoic acids, dihydrobenzyl alcohols $\left(1, \mathrm{R}=\mathrm{CH}_{2} \mathrm{OH}\right)$ have also been used as precursors (D. Kuck, unpublished results).

Fragmentation of other cyclic olefins, notably monoterpenes (44), under EI conditions is well known to give $\mathrm{C}_{7} \mathrm{H}_{9}{ }^{+}$ions, which exhibit the characteristics of toluenium ions (45). A straightforward example is $\alpha$-phellandrene 8 (46), which could form toluenium ions by loss of $\mathrm{C}_{3} \mathrm{H}_{7}{ }^{\cdot}$ without preceding rearrangement.

\section{Fragmentation with rearrangement or cyclization}

Electron impact mass spectra of most monoterpenes exhibit abundant $\mathrm{C}_{7} \mathrm{H}_{9}{ }^{+}$ peaks $(44,46,47)$ in spite of a considerable skeletal reorganization required for loss of $\mathrm{C}_{3} \mathrm{H}_{7}$. In all cases, toluenium ions appear to be produced, as suggested by Schwarz et al. (46) on the basis of collision-induced dissociation (CID) spectra. In a related work, Levsen and Hilt (48) found closely similar CID spectra for $\mathrm{C}_{6} \mathrm{H}_{7}{ }^{+}$ ions formed from various unsaturated hydrocarbon precursors. Hexatrienes and the cyclohexadienes give $\mathrm{C}_{6} \mathrm{H}_{7}{ }^{+}$ion mixtures containing the benzenium isomer, as first suggested by Franklin and Carroll (49), but varying amounts of other 

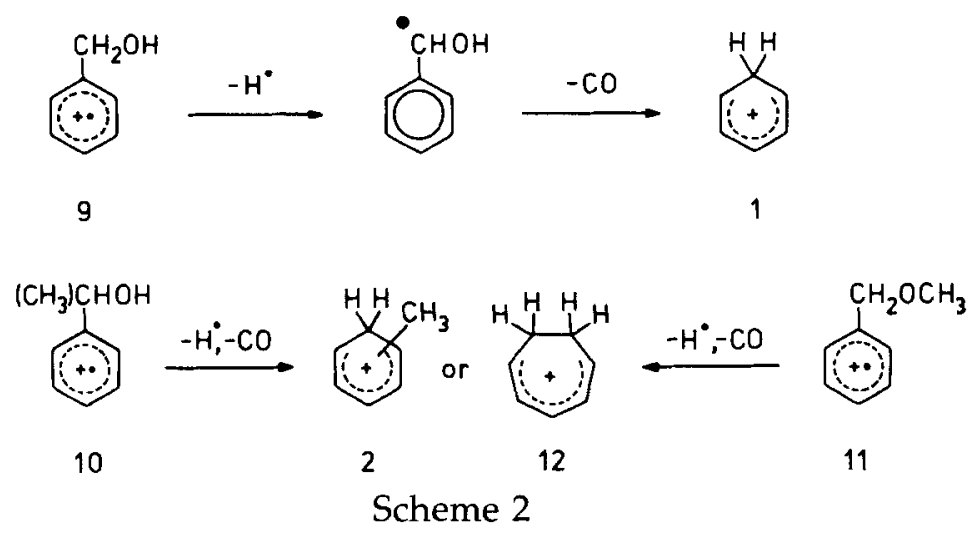

isomers as well, as shown later by Allan et al. (50) by using the PEPICO technique. In a recent study, Lias and Ausloos (51) quantified the benzenium fraction and identified at least three further, nonbenzenium $\mathrm{C}_{6} \mathrm{H}_{7}{ }^{+}$structures from these precursors.

Many functionalized benzenes give $\mathrm{C}_{6} \mathrm{H}_{7}{ }^{+}, \mathrm{C}_{7} \mathrm{H}_{9}{ }^{+}$, and related ions of low to moderate relative abundance in the standard EI mass spectra. The radical cations of benzyl alcohol (9, Scheme 2) form $\mathrm{C}_{6} \mathrm{H}_{7}{ }^{+}(52)$, and those of 1-phenylethanol 10 (46) and benzyl methyl ether 11 (53) give $\mathrm{C}_{7} \mathrm{H}_{9}{ }^{+}$, though, in the latter case, in very low relative abundance. Whereas the benzenium structure 1 for $\mathrm{C}_{6} \mathrm{H}_{7}{ }^{+}$is certain beyond any doubt, the dihydrotropylium ion structure 12 was suggested for the $\mathrm{C}_{7} \mathrm{H}_{9}{ }^{+}$ions (Section III.B.3). Williams and Hvistendahl (54) reported that both $\mathrm{C}_{6} \mathrm{H}_{7}{ }^{+}$and $\mathrm{C}_{7} \mathrm{H}_{9}{ }^{+}$ions formed by $\mathrm{EI}$ from different sources react like those formed by protonation of benzene and toluene, respectively, under $\mathrm{CI}$ conditions (see also refs. 41,42).

Benzenium and alkylbenzenium ions may be also formed from ionized alkylbenzenes under EI conditions. Thus ions $\mathrm{C}_{8} \mathrm{H}_{9}{ }^{+}(\mathrm{m} / \mathrm{z}$ 105) are prominent primary fragments in the EI mass spectra of alkylbenzenes (see Part I); in a secondary fragmentation step they eliminate $\mathrm{C}_{2} \mathrm{H}_{2}$ to give, most probably, benzenium ions (55). Harrison et al. $(56,57)$ collected the appearance energy data and apparent heats of formation of $\mathrm{C}_{6} \mathrm{H}_{7}{ }^{+}$and $\mathrm{C}_{7} \mathrm{H}_{9}{ }^{+}$ions from various unsaturated and aromatic precursors. The strikingly similar fragmentation of methyl-substituted cyclopentadienes and cyclohexadienes, in particular, with those of alkylbenzenes strongly suggested the formation of benzenium-type fragment ions. Related results were published independently by Franklin and Carroll (49) and Winters and Collins (58).

Another indirect channel to benzenium-type fragment ions is due to intramolecular electrophilic attack of a carbenium center, formed upon primary fragmentation, on a benzene nucleus. An example, taken from an EI spectrum of a typical "complex" organic molecule, is shown in Scheme 3 (D. Kuck, to be published). Loss of the 3-benzyl group from 3-benzyl-1,5-diphenylpentane radical cation (13) produces a secondary carbenium ion (14), which attacks one of the remaining benzene rings, giving rise to a protonated indan derivative (15). Subsequent elimination of benzene ("protonolysis"), after ring-to-ring proton transfer, 


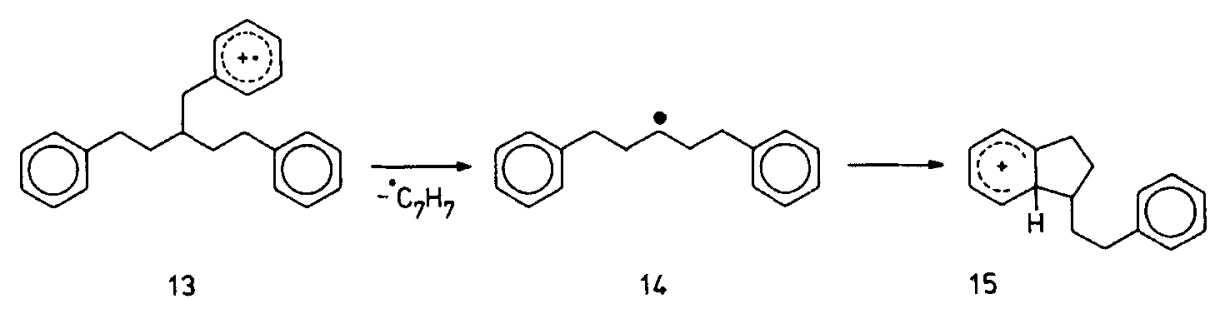

Scheme 3

is a characteristic feature of these species. Further examples for large alkylbenzenium ions will be discussed in Section VIII.

\section{Distonic ions with benzenium ( $\sigma$-complex) group}

There is a third way to form benzenium-type ions from El-generated radical cations of alkylbenzenes, hidden among the multitude of isomerization and fragmentation processes occurring in the EI source. Hydrogen atom migration from a $\gamma-\mathrm{C}-\mathrm{H}$ donor site of the side chain to the ortho or ipso position of the ionized benzene ring may generate a $\sigma$-complex species bearing an electronically isolated radical center at the $\mathrm{C}^{\gamma}$ atom (Scheme 4). The formal $\gamma$ - or $\delta$-distonic ions thus formed have been discussed in Part I and in Hammerum's comprehensive review on distonic ions (59). Formation of such transient $\sigma$-complexes with "ortho protonation" (e.g., 17) is recognized by extensive, albeit highly regioselective, intramolecular H/D exchange $(60,61)$. Transfer of the hydrogen atom to the ipso position is promoted by electron-donating substitutes (e.g., $18 \rightarrow 19$ ) and leads to the loss of neutral arenes. It has been shown recently that, in a corresponding way, hydrogen transfer to "methyl-blocked" ortho positions can be explained by formation of $\sigma$-complex intermediates (e.g., $20 \rightarrow 21)(62,63)$.

These few examples may show that the formation of $\sigma$-complexes (or benzenium-type ions) from alkylbenzenes is not at all restricted to even-electron species formed by $\mathrm{Cl}$ or ion-molecule reactions (see next section). By contrast, whenever benzene or a substituted benzene is eliminated from a radical cationic species, an ipso- (or, in general, ring-) protonated $\sigma$-complex may be involved. For further examples, the reader is referred to Part I.

\section{Benzenium ions by ion-molecule reaction of radical cations}

Benzenium ions are also generated by intermolecular hydrogen transfer reaction (Scheme 5) $(64,65)$.

Ion-molecule reactions between ionized allene or propyne with their neutral precursors lead also to mixtures of isomeric $\mathrm{C}_{6} \mathrm{H}_{7}{ }^{+}$ions containing varying amounts of ions 1 (66-69). In a recent ICR study, Lias and Ausloos (51) determined these fractions by monitoring the deprotonation of ions 1 by various bases.

Gross and co-workers (70-72) and Audier et al. (73) investigated the reaction of ionized benzene with alkyl halides. Alkyl iodides, in particular, form adducts 


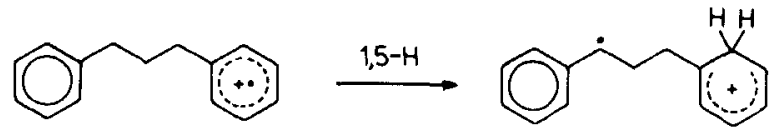

16<smiles>COc1ccc(CC2Cc3ccccc3C2)cc1</smiles>

18

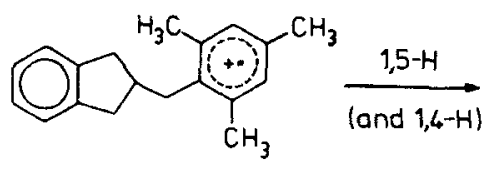

20
17<smiles>COc1ccc(CC2Cc3ccccc3C2)cc1</smiles>

19<smiles>Cc1cc(C)c(CC2Cc3ccccc3C2)c(C)c1</smiles>

Scheme 4

22 which expel an iodine atom to give the corresponding alkylbenzenium ions (e.g., 5) (Scheme 5).

\section{B. Benzenium and alkylbenzenium ions by protonation and addition reactions}

The chemistry of protonated alkylbenzenes produced by CI mass spectrometry has not been treated comprehensively up to now. After Munson and Field's first reports $(3,4)$, this topic was addressed briefly in some more general treatments $(5,27)$. In the present review, the formation of benzenium and alkylbenzenium ions by $\mathrm{CI}$ and ion-molecule reactions is divided in three sections: (1) Protonation by the reactant gas or by another protonated arene; (2) alkylation by stable, electrophilic organic or inorganic ions, and (3) addition (insertion) of phenyl cations into $\mathrm{C}-\mathrm{H}$ and $\mathrm{C}-\mathrm{C} \sigma$ bonds.

Proton affinity data are available for most of the simple alkylbenzenes and their

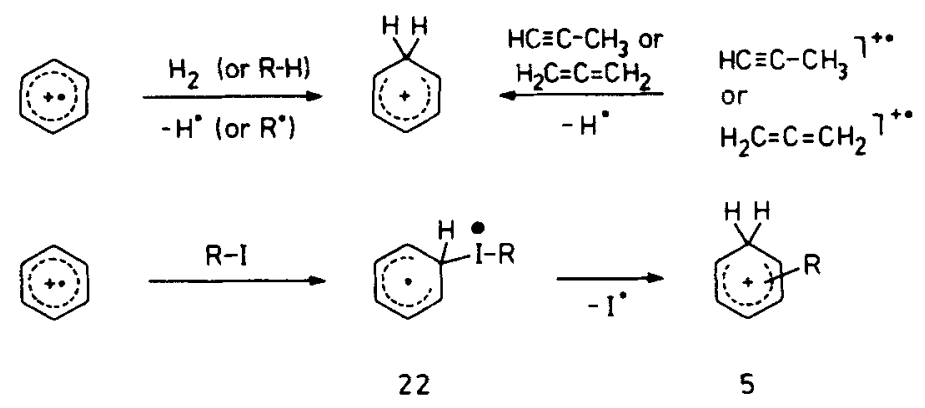

Scheme 5 


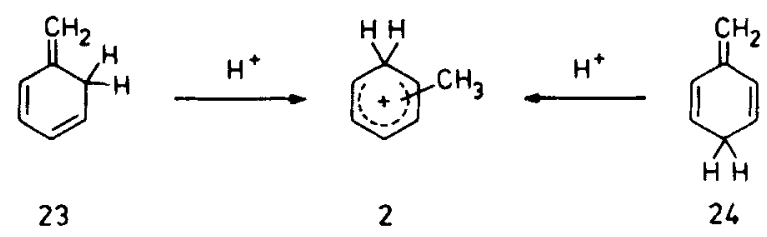<smiles>C=C1C(C)=C(C)C(C)(C)C(C)=C1C</smiles>

25

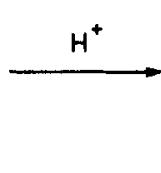

Scheme 6

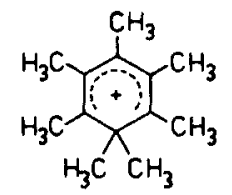

26

derivatives. PA values on more complex systems, such as diphenylalkanes are scarce, however (30). The local proton affinities of alkylbenzenium ions will be discussed where appropriate; for global PA values the reader is referred to recent compendia $(27,28,30)$.

\section{Protonation}

Benzene is a fairly strong base in the gas phase, with a proton affinity (PA) of $181.3 \mathrm{kcal} \cdot \mathrm{mol}^{-1}(74,75$; see also 76,77$)$; it is protonated exothermically by using $\mathrm{CH}_{5}{ }^{+}$and $\mathrm{C}_{2} \mathrm{H}_{5}{ }^{+}$reactant ions. By contrast, protonation is thermoneutral with $\mathrm{C}_{3} \mathrm{H}_{7}{ }^{+}$and endothermic with $t-\mathrm{C}_{4} \mathrm{H}_{9}{ }^{+}$. Protonation of benzene and alkylbenzenes has been performed with moderately acidic reactant ions such as $\mathrm{H}_{3} \mathrm{O}^{+}$and $\mathrm{CI}$ gas mixtures such as $\mathrm{H}_{2} / \mathrm{CO}, \mathrm{H}_{2} / \mathrm{N}_{2}$, in which $\mathrm{N}_{2} \mathrm{H}^{+}$and $\mathrm{CHO}^{+}$, respectively, might be the proton-transferring reagent ions (5). Other reactant ions are even stronger than $\mathrm{CH}_{5}{ }^{+}$. The most aggressive among these, $\mathrm{H}_{3}{ }^{+}$and $\mathrm{HeH}^{+}$, have been used by Cacace and colleagues (24-26) in a large number of studies. These workers have combined, in recent years, the investigation of the "high-pressure" gas-phase chemistry of alkylbenzenium ions, utilizing radiolytic and nuclear decay techniques $(26,78)$, with the conventional low-pressure behavior obtained by CI and ICR mass spectrometry.

In some cases, alkylbenzenium ions have been generated from the corresponding "isoarenes" (methylenecyclohexadienes), providing another independent access to these ionic systems (Scheme 6). For example, ortho- and para-isotoluenes 23 and 24, respectively, have been used as unusual neutral precursors (79; see also Part 1). The hexamethyl derivative (25) has been used to generate heptamethyltoluenium ions 26 (80).

\section{Alkylation}

The formation of $\left[\mathrm{M}+\left(\mathrm{C}_{n} \mathrm{H}_{2 n+1}\right)\right]^{+}$ions is a general reaction in the $\mathrm{CI}$ plasma of methane, propane, or isobutane used as the reagent gas. These adduct ions 


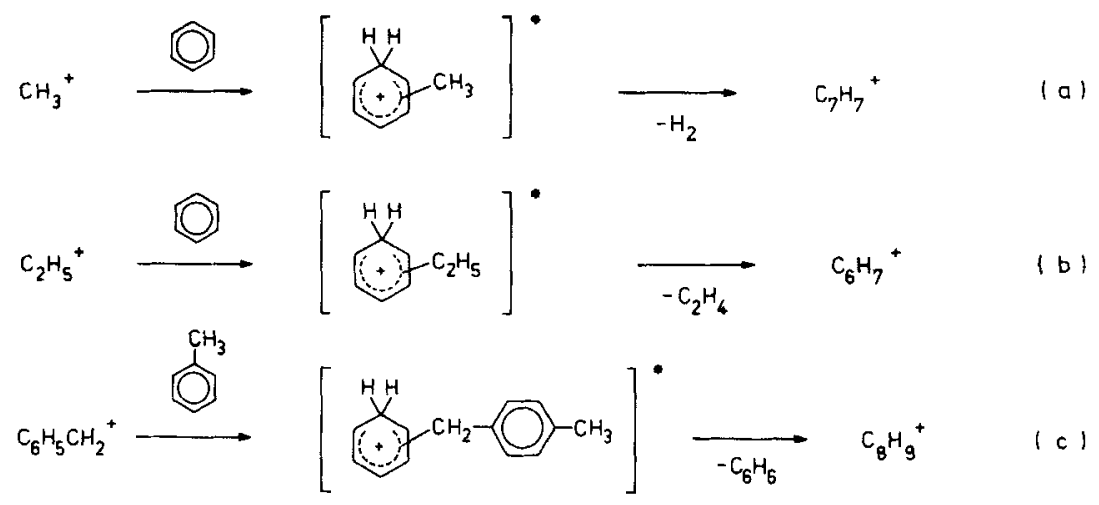

Scheme 7

exhibit the same reaction as the $[\mathrm{M}+\mathrm{H}]^{+}$ions of the corresponding alkylbenzenes and have been studied intensively. A broad range of alkylating ions, including $\mathrm{CH}_{3}{ }^{+}, \mathrm{CH}_{2} \mathrm{X}^{+}\left(\mathrm{X}=\mathrm{ClCH}_{3}, \mathrm{ClC}_{2} \mathrm{H}_{5}, \mathrm{FCH}_{3}\right.$, etc. $)$ has been studied by pressurevariable techniques $(78,81)$. Since most of the alkylation reactions are highly exothermic, the observation of the adduct ions depends on the efficiency of collisional stabilization. Without such deactivation, the typical products of alkylbenzenium ions are observed instead of the adduct ions. Some examples are shown in Scheme 7.

Likewise, the extent of isomerization by hydrogen exchange and skeletal reorganization is a highly pressure-dependent process. The isomerization of the "adduct ions" and their fragmentation reactions is discussed in detail in Section III. If collisional stabilization is achieved, these alkylation reactions can be used, in turn, to distinguish between isomeric electrophils, as shown by Lay and Gross (82) and Kieu My et al. (83) for $\mathrm{C}_{3} \mathrm{H}_{5}{ }^{+}$(allyl and propenyl) ions. Reaction (c) has been used extensively to estimate the fraction of reactive $\mathrm{C}_{7} \mathrm{H}_{7}{ }^{+}$(benzyl) ions in mixtures with their inert tropylium isomers. The degeneracy of this process without collisional stabilization has been tackled by studying the unimolecular loss of benzene from protonated diphenylmethane (84; see Section VIII.C).

\section{Addition of dihydrogen, alkanes, and alkenes to phenyl cations}

Speranza et al. (85) have shown that phenyl cations are extremely strong electrophiles in the gas phase. They react with $\mathrm{H}_{2}$ and alkanes by formal insertion into the $\mathrm{H}-\mathrm{H}$ and $\mathrm{C}-\mathrm{H} \sigma$ bonds, respectively, to give benzenium or the corresponding alkylbenzenium ions (Scheme 8 ). Without collisional stabilization [as in the original ICR study (85)], only $\mathrm{C}_{7} \mathrm{H}_{9}{ }^{+}(2)$ ions were observed in addition to the corresponding fragment ions. By contrast, reaction with ethane and propane at higher pressures leads to formation of protonated ethyl- and isopropylbenzene via $\mathrm{C}-\mathrm{H}$ rather than $\mathrm{C}-\mathrm{C}$ bond insertion (86). Small alkenes add to phenyl cations as well, whereas cyclopropane transfers a methylene group to give $\mathrm{C}_{7} \mathrm{H}_{7}{ }^{+}$ ions (87).

The addition of $\mathrm{H}_{2}$ and $\mathrm{CH}_{4}$ to phenyl and tolyl cations formed from the cor- 


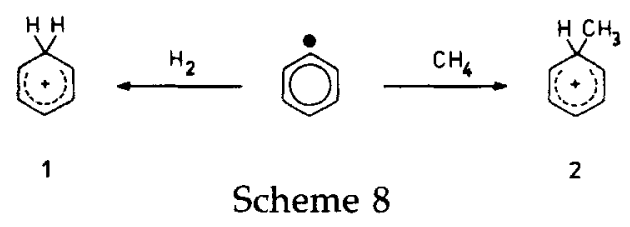

responding haloarenes in the $\mathrm{Cl}$ plasma was studied extensively by Harrison and others $(46,88-91)$. Cacace and Speranza $(92,93)$ observed similar reactions in dilute gas radiolysis experiments. It was found (90) that this ion-molecule reaction provides a positive structural probe for tolyl ions, in contrast to benzyl and tropylium $\mathrm{C}_{7} \mathrm{H}_{7}{ }^{+}$isomers (see Part I). Blom and Munson (94) studied this addition reaction in a $\mathrm{CI}$ source modified by additional regions for high-pressure collisional activation (HPCA) and ion-molecule reactions. Recently, the $\mathrm{C}-\mathrm{H}$ insertion reaction has been observed in the collision region of a triple-stage quadrupole instrument as well $(41,95)$. Addition of $\mathrm{CH}_{4}$ leads to (initially) ipso protonated toluenes which then may undergo isomerization by hydrogen exchange and skeletal rearrangement.

\section{STRUCTURE AND UNIMOLECULAR REACTIONS OF BENZENIUM ION AND LOWER ALKYLBENZENIUM IONS}

\section{A. Protonated benzene, $\mathrm{C}_{6} \mathrm{H}_{7}{ }^{+}$}

\section{Structure}

A long-standing problem of organic chemistry is directly connected to protonation of benzene; that is, the question as to what are the structures and relative energies of intermediates and the final product in the formation of protonated benzene, $\mathrm{C}_{6} \mathrm{H}_{7}{ }^{+}$. This relevance originates, of course, from the central role of protonated benzene as the prototypical intermediate of electrophilic aromatic substitution $(8,9)$.

Today, the $\sigma$-complex 1 (Scheme 9) (96), as the prototype of Pfeiffer-Wizinger complexes (97) or Wheland intermediates (98), is accepted as the most stable form of $\mathrm{C}_{6} \mathrm{H}_{7}{ }^{+}$both in solution and in the gas phase. In this review, covalently bonded adducts of type 1 will be called "benzenium ions", according to Olah's (99) suggestion. In general, a $\sigma$-complex structure will be implicated as the most stable form for the $[\mathrm{M}+\mathrm{H}]^{+}$ions of all alkylbenzenes. Several $\pi$ complexes ("sideon," 27 and 28, and "face-on," 29) have been considered and are all less stable than 1.

The most convincing experimental evidence for $\mathbf{1}$ as the most stable structure comes from NMR studies in superacid solution by Olah et al. $(100,101)$. Support for 1 as the most stable form in the gas phase is only indirect, for example from the increase of the proton affinity $\mathrm{PA}\left(\mathrm{C}_{6} \mathrm{H}_{5}-\mathrm{X}\right)$ of substituted benzenes. Strict consideration of the experimental facts does not exclude the possibility that the gaseous $\pi$ complex structure is more stable than the $\sigma$-complex. In fact, early computational work had corroborated this view $(102,103)$. However, the over- 


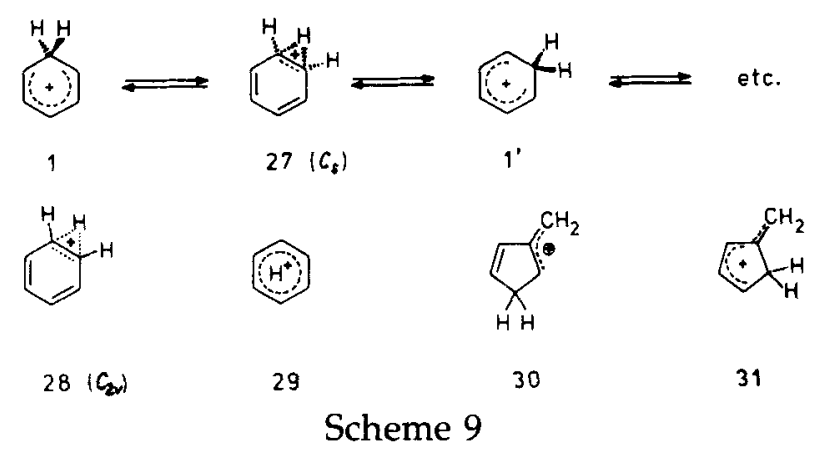

whelming majority of theoretical studies, both $a b$ initio and semiempirical, suggest the $\sigma$-complex structure to be the most stable $\mathrm{C}_{6} \mathrm{H}_{7}{ }^{+}$isomer $(29,104-115)$. The presently accepted view is that structure 1 is more stable than 27 by some $5-7$ $\mathrm{kcal} \cdot \mathrm{mol}^{-1}$, whereas the face-protonated form 29 is far less stable. However, recent arguments on the gas-phase chemistry of protonated benzenes by Mason et al. (29) suggest that the $\pi / \sigma$ complex discussion is to be continued.

\section{Isomerization}

Dynamic nuclear magnetic resonance (NMR) studies by Olah et al. $(100,101,116)$ yielded the Arrhenius activation energy $E_{a}=10 \pm 1 \mathrm{kcal} \cdot \mathrm{mol}^{-1}$ and a pre-exponential factor of $10^{15.9 \pm 1.6} \mathrm{~s}^{-1}\left(\Delta G^{*}=8 \mathrm{kcal} \cdot \mathrm{mol}^{-1}\right)$ for the intramolecular (degenerate) interconversion of benzenium ions 1 at $170 \mathrm{~K}$. No experimentally determined value is known for the gas phase, but evidence from isomerization behavior of higher alkylbenzenium ions points to similar or even lower interconversion barriers. In most of the computational approaches cited above, the sideprotonated ("strong") $\pi$-complex $\mathbf{2 7}$ is considered to represent the transition state. Some authors suggested that this $\pi$-complex resides in a shallow energy well (of $\simeq 1 \mathrm{kcal} \cdot \mathrm{mol}^{-1} \mathrm{depth}$ ) (109). Hence the remarkably large range of computationally determined activation energies published over the years $\left(20 \geq E_{a} \geq 0 \mathrm{kcal} \cdot \mathrm{mol}^{-1}\right)$ seems to stabilize at the above-mentioned range of 5-7 kcal-mol ${ }^{-1}$. In their extensive discussion of thermodynamics of proton transfer reactions in arene/arenium ions systems, Mason et al. (29) estimated the activation barrier to be $\leq 5.5 \mathrm{kcal} \cdot \mathrm{mol}^{-1}$. Thus, consecutive 1,2-hydride shifts $1 \rightleftarrows 27 \rightleftarrows 1$ etc., often (perhaps erronously) termed proton ring-walk, can be compared with the similarly facile 1,2-hydride shift in ethyl cation, $\mathrm{C}_{2} \mathrm{H}_{5}{ }^{+}$(see Section III.C.2).

The hydrogen ring-walk in 1 represents a ubiquitous isomerization channel in alkylbenzenium ions. Several other types of rearrangements (skeletal isomerization including alkyl shifts, inter-ring proton transfers) have been observed in various cases but are generally less favorable. In fact, all constitutional isomers of the parent benzenium ion 1 are less stable, as confirmed recently in a detailed study by Lias and Ausloos (51). It is worth noting, however, that the isomer closest in energy (3-protonated fulvene, 30) is only $10 \mathrm{kcal} \cdot \mathrm{mol}^{-1}$, and others, such as 31 , are only $20 \mathrm{kcal} \cdot \mathrm{mol}^{-1}$, less stable than 1 . Hence carbon scrambling 
cannot be excluded for extremely exothermic protonation conditions [e.g., under $\left.\mathrm{CI}\left(\mathrm{H}_{2}\right)\right]$.

\section{Fragmentation}

Benzenium 1 ions undergo two major fragmentation reactions, viz. loss of $\mathrm{H}^{*}$ and loss of $\mathrm{H}_{2}$. The latter is the reverse of the $\mathrm{H}_{2}$ addition (Scheme 8) and highly energy-demanding $\left(\Delta H_{r}=65 \mathrm{kcal} \cdot \mathrm{mol}^{-1}\right)$, but the former is even more so $\left[\Delta H_{r}\right.$ $=81 \mathrm{kcal} \cdot \mathrm{mol}^{-1}$, see also ref. 117]. Accordingly, the $\mathrm{H}_{2}$ elimination is the major fragmentation of metastable 1 ions and upon photodissociation (PD) of the stable ions, whereas $\mathrm{H}^{*}$ loss gains importance upon collisional activation (118). Elimination of $\mathrm{H}_{2}$ has been interpreted as a simple (Woodward-Hoffmann allowed) $[1,1]$-extrusion reaction $(54,119)$; it is one of the rare $\mathrm{H}_{2}$ elimination reactions associated with a negligibly small kinetic energy release $\left[\mathrm{T} \simeq 0 \mathrm{kcal} \cdot \mathrm{mol}^{-1}\right)(119,120)$, in contrast to $\mathrm{H}_{2}$ loss from protonated toluene and xylene (see below). The gasphase PD spectra of benzenium (as well as of mesitylenium) ions were investigated by Freiser and Beauchamp $(121,122)$. McMahon et al. (123) recently described the neutralization-reionization mass spectra (NRMS) of deuterium-labelled benzenium ions.

\section{B. Toluenium and other methylbenzenium ions}

Similarly to the radical cations of toluene, the xylenes, and other methylbenzenes, discussed in detail in Part I, the presence of the methyl substituent(s) in the benzenium ion induces drastic changes in their isomerization and fragmentation behavior. In the first article addressed to the unimolecular chemistry of gaseous methylbenzenium ions, Field (124) investigated the fragmentation of $\mathrm{C}_{7} \mathrm{H}_{9}{ }^{+}$ions from toluene, cycloheptatriene, and norbornadiene occurring in the $\mathrm{CI}\left(\mathrm{CH}_{4}\right)$ source. Inspired by the skeletal rearrangement phenomena found with the corresponding radical cations $(125,126)$, this classic report contains some important considerations on the ring expansion of (alkyl)toluenium ions, on the one hand, and on the ring contraction of protonated (alkyl)cycloheptatriene, on the other. More detailed insights were worked out later by using metastable ion techniques. It could in fact be demonstrated that besides the fast hydrogen ringwalk, reversible skeletal isomerization does occur in toluenium $\left(\mathrm{C}_{7} \mathrm{H}_{9}{ }^{+}\right)$and $x y-$ lenium ions $\left(\mathrm{C}_{8} \mathrm{H}_{11}{ }^{+}\right)$, in parallel to the isomerization behavior of the radical cationic relatives $\left(\mathrm{C}_{7} \mathrm{H}_{8}{ }^{+}\right.$and $\left.\mathrm{C}_{8} \mathrm{H}_{10}{ }^{+\bullet}\right)$.

The fragmentation of methylbenzenium ions is particularly simple and will be discussed where appropriate. Loss of a hydrogen atom from methylbenzenium ions is a minor process under low-energy conditions. CID spectra, of course, show this simple fragmentation as a major fragmentation path (118). From pertinent thermochemical data Holmes and Lossing (117) recently pointed out that the $\alpha-C-H$ bonds in toluenium ions 2 are $\simeq 8 \mathrm{kcal} \cdot \mathrm{mol}^{-1}$ stronger than the ring $\mathrm{C}-\mathrm{H}$ bonds; this is in contrast to those of the radical cations of toluene. The consecutive fragmentations of methylbenzenium ions have been analyzed by Blom and Munson (94). 


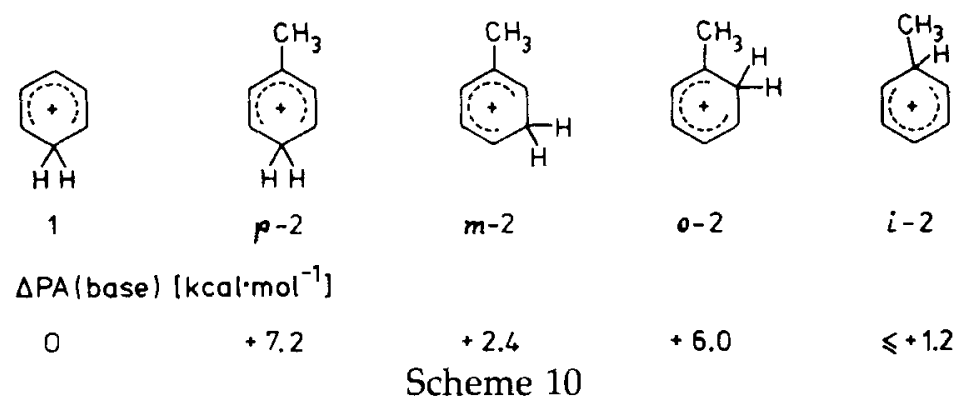

\section{Structures and local proton affinities}

Klotz et al. (127) reported in 1968 that the proton affinities and gas-phase basicities of benzene increase with increasing degree of methyl substitution. In later work, they found opposite trends for the cross section and the exothermicity of protonation of these arenes by $\mathrm{H}_{3} \mathrm{O}^{+}(128)$, indicating a fundamentally different kinetic and thermodynamic behavior of alkylbenzenes upon protonation in the gas phase (129); see Section VII.B).

According to all experimental and computational evidence, the $\sigma$ complex is the most stable structure of protonated toluene and all other alkylbenzenium ions. Devlin et al. (130) determined the relative proton affinities of toluene and several other methylbenzenes by ICR mass spectrometry and $a b$ initio calculations. At the same time, Heidrich et al. (131) performed semiempirical calculations to estimate the relative stabilities of tautomeric toluenium ions. Recently, Dewar and Dieter (115) calculated some toluenium ion tautomers by using the semiempirical AM1 method. From Devlin's studies (130), proton affinity increments were assigned to the individual ring positions and shown to be additive, in line with experiment. As a key set of local proton affinity data in many more complex ionic systems, the site-specific PAs of toluene were determined (Scheme 10). Thus, the para position is more basic than the methine groups of benzene by $7-8 \mathrm{kcal} \cdot \mathrm{mol}^{-1}$, and the ipso position is almost unchanged (130).

The additivity of the local PA increments is indeed remarkable. Its general validity has been used recently to rationalize the fragmentation of ionized polyalkylbenzenes (62). It strongly corroborates the formation of $\sigma$-rather than $\pi$ complexes in the gas phase. The preferred formation of para and ortho tautomers accounts for the relative overall (global) proton affinities of toluene and other methyl- and alkylbenzenes $(27,28,30,74,75,130,132)$. Catalán and Yánez $(133,134)$ showed that the local PA of substituted benzenium ions can be predicted from the $a b$ initio $1 s$ orbital energies.

The particular stability of the gaseous para-toluenium ion $p$-2 corresponds to Olah's observation of this species and of homologous para-alkylbenzenium ions as the only, static tautomer in superacid solution at low temperatures $(10,101)$. In line with the above results, however, Fărcaşiu et al. $(135,136)$ observed a minor fraction of ortho-ethylbenzenium ions along with the major para tautomer. 


\section{Hydrogen ring walk and methyl shifts}

The hydrogen ring walk in substituted benzenium ions is markedly affected by substituents. As shown above, the relative stabilities of the tautomeric forms of methylbenzenium ions vary by $\simeq 0-8 \mathrm{kcal} \cdot \mathrm{mol}^{-1}$ per methyl group in a fairly additive manner; with more polar substituents such as $\mathrm{OCH}_{3}$ the local PAs are even more different. As a consequence, the intermolecular hydrogen $\left(\mathrm{H}^{+} / \mathrm{D}^{+}\right)$ exchange may occur with high and energy-dependent positional selectivity, as shown by CI-MS $(137,138)$ and ICR $(139)$ studies of various substituted benzenes (Section VII.B). In these cases, of course, the protons at the benzenium ion do not undergo equilibration by fast hydrogen ring walk.

Besides their effect on the different stabilities of the tautomeric $\sigma$-complexes, alkyl groups seem to increase the activation barriers for the proton ring walk by several $\mathrm{kcal} \cdot \mathrm{mol}^{-1}$, as deduced by Heidrich et al. from semiempirical calculations on protonated toluene and xylenes $(131,140)$. According to these studies, however, the ipso-toluenium structure $(i-2)$ requires only $\simeq 4 \mathrm{kcal} \cdot \mathrm{mol}^{-1}$ activation energy to isomerize exothermically to the ortho tautomer $(0-2)$, in line with the Hammond postulate. The effect of solvation on the stability order and the ease of the proton ring walk in toluenium and xylenium ions has also been studied (141). In general, the solvation of protonated benzenes seem to disfavor the stability of the $\pi$-complexes and hence increase the barrier of the proton ring walk. However, the experimental activation barriers for protonated ortho-xylenes $\left(m^{\prime}\right.$ $32 \rightarrow m-32$ and $m-32 \rightarrow 0-32$, Scheme 11) in superacid solution reported by Olah and Mo $(142,143)$ are significantly lower $\left(5.3\right.$ and $\left.6.4 \mathrm{kcal} \cdot \mathrm{mol}^{-1}\right)$ than that found for the unsubstituted benzenium ion under these conditions. The relative ease of intra-annular and interannular proton exchange has gained some relevance for the isomerization of alkylbenzenium ions with more than one benzene ring (Section VIII).

The hydrogen ring walk in methylbenzenium and halogenotoluenium ions has been discussed recently in terms of internal translation of the extra proton (29). Unexpectedly high entropies of protonation were measured by HPCI mass spectrometry for various arenes including the xylenes and halogenotoluenes (144146). The effect is most pronounced with those isomers that can form several easily interconverting $\sigma$-complexes. For example, para-xylene (cf., $0-33 \rightleftarrows o^{\prime}-33$ ) and para-fluoro-toluene exhibit higher protonation entropies than the meta isomers, the latter having particularly basic, hence "isolated", meta positions.

Cacace and co-workers $(147,148)$ studied the protonation of benzene and toluene by $\mathrm{H}_{3}{ }^{+}$or $\mathrm{HeH}^{+}$ions in hydrogen atmosphere at room temperature and observed a very low substrate selectivity, in accordance with the extreme exothermicity of the reactions. However, the isotope incorporation in toluene was remarkably regioselective. It has been argued that under these unusual conditions (in terms of mass spectrometry) the equilibration of the hydrogen atoms may be essentially suppressed by collisional deactivation of the initially formed toluenium ions.

In contrast to the hydrogen ring walk, methyl shifts have been found less frequently in gaseous protonated methylbenzenes. From solution chemistry, many 


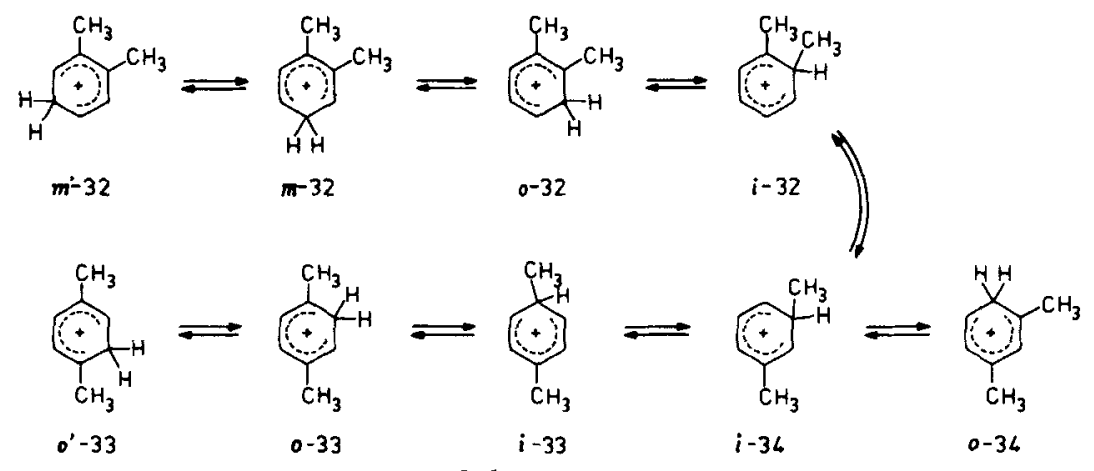

Scheme 11

examples are known for acid-catalyzed methyl ring walk, including the whole range of methylbenzenium ions from toluenium (149) to heptamethylbenzenium ions (150). Ortho- and para-xylene rearrange to the meta isomer in superacid solution $(12,151)$, due to the particular stability of the meta-xylenium ion $0-34$ (Scheme 11). In general, the activation barriers for the methyl shift are significantly higher $\left(17-22 \mathrm{kcal} \cdot \mathrm{mol}^{-1}\right)$ than those toward the hydrogen shift. Accordingly, methyl shifts in gaseous methylbenzenium ions have been found only in highly excited methylbenzenium ions.

Cacace et al. $(152,153)$ studied the electrophilic attack of (unsolvated) $\mathrm{CH}_{3}{ }^{+}$ ions on benzene and toluene both in the liquid and the dilute gas phase, utilizing the nuclear decay of tritated methane, $\mathrm{CT}_{4}$. The high exothermicity of these reactions $\left(\Delta H r \simeq-94 \mathrm{kcal} \cdot \mathrm{mol}^{-1}\right)$ causes extensive methyl ring walk in the excited methylbenzenium ions prior to deprotonation, as follows from the distribution of isomeric xylenes. At low pressures, thermodynamic control leads to predominant formation of meta-xylene. At high pressures and in the liquid phase, however, the less stable para- and ortho-xylenium ions $\mathbf{3 2}$ and $\mathbf{3 3}$ formed under kinetic control are deprotonated fast enough to give the respective neutral xylenes as the major products (Scheme 11).

It is worth noting that the methyl ring walk in protonated methylbenzenes has not been identified by mass spectrometric techniques up to now. As pointed out in Part I, the distinguishability of the xylenes by mass spectrometric methods is poor. One possibility (154) takes advantage of their different gas-phase basicities (27). Under more energetic conditions required for the methyl ring walk, soft proton transfer reactions cannot be used. Kuck, Richter et al. (42), however, recently found that a fraction of highly excited xylenium ions undergo the methyl ring walk in competition with skeletal isomerization by reversible ring expansion (see next section).

The gaseous hexamethylbenzenium ion and its isomer, protonated hexamethyl (Dewar benzene), have been studied by photodissociation spectroscopy (155) and CID mass spectrometry (156). The PD Mass spectra of both ions are much similar to those of protonated mesitylene $(121,122)$ as well as to the ultraviolet (UV) spectrum of the arene in superacid solution and, therefore, indicate that the latter ion rapidly isomerizes to the arenium ion. Accordingly, the CID spectra are in- 
distinguishable, in contrast to that of the $\mathrm{NO}^{+}$adduct ion (156). The heptamethylbenzenium ion, known as a stable salt and as the only methyl- $\mathrm{C}-\mathrm{H}$ acidic benzenium ion in solution (157), was studied in the gas phase by Attinà et al. (80), and the $\sigma$-complex structure has been assigned to it. However, no details concerning the methyl shift isomerization were reported. Methyl shifts (as well as fluorine shifts, see Section VII.B.2) were postulated by Mason et al. (29) to occur in para-fluorotoluenium ions above $450 \mathrm{~K}$ giving rise to the more stable meta isomer.

\section{Skeletal rearrangement reactions}

In an attempt to correlate the Woodward-Hoffmann rules $(158,159)$ to mass spectrometric phenomena, Williams and Hvistendahl $(119,120,160)$ pointed out that the loss of $\mathrm{H}_{2}$ from metastable toluenium ions 2, in contrast to benzenium ions 1, is accompanied by an extremely large kinetic energy release [ $\mathrm{T}=19-23$ $\mathrm{kcal} \cdot \mathrm{mol}^{-1},(120)$, see also ref. 35 and, with some care, ref. 46]. This observation was explained by assuming a ring expansion of ions 2 to protonated cycloheptatriene 12 (dihydrotropylium ions) followed by an orbital-symmetry forbidden 1,2- (or 1,3-) elimination of $\mathrm{H}_{2}$ to give tropylium ions 37 as the final products (Scheme 12). On the basis of standard CI mass spectra, Field (124) discussed this ring expansion reaction in comparison to the chemistry of gaseous $\mathrm{C}_{7} \mathrm{H}_{8}{ }^{+}$ions (Part I).

By using the EI approach to generate (alkyl)benzenium ions (Section II.A.1), Kuck et al. (35) analyzed the isotope scrambling preceding the loss of $\mathrm{H}_{2}$ and in particular the loss of $\mathrm{CH}_{4}$, which constitutes a second, albeit minor, fragmentation reaction in long-lived toluenium ions (Scheme 12). $\mathrm{CH}_{4}$ loss was observed earlier by Aliquanti et al. (161) in pressure-dependent CI experiments with toluene and the xylenes. The kinetic energy released during $\mathrm{CH}_{4}$ loss from metastable toluenium ions is very small $\left[\mathrm{T} \simeq 0.8 \mathrm{kcal} \cdot \mathrm{mol}^{-1}\right.$ (35), see also ref. 46$]$, similar to that of the $\mathrm{H}_{2}$ loss from benzenium ions. Competition of the highly endothermic $\mathrm{CH}_{4}$ loss $\left(\Delta H_{r}=63 \mathrm{kcal} \cdot \mathrm{mol}^{-1}\right)$ with $\mathrm{H}_{2}$ loss $\left(\Delta H_{r} \simeq 19-25 \mathrm{kcal} \cdot \mathrm{mol}^{-1}\right)$ is indeed due to the enormous activation barrier toward $\mathrm{H}_{2}$ loss $\left(E^{*} \geq 48 \mathrm{kcal} \cdot \mathrm{mol}^{-1}\right)$, allowing for several isomerization processes to occur. It was found, however, that $35 \%$ of the methane lost from $\alpha-{ }^{13} \mathrm{C}$-labelled toluenium ions contained a ring carbon atom, clearly indicating that the ring expansion reaction to dihydrotropylium ions 12 is reversible. Further deuterium labelling revealed that metastable toluenium ions 2 undergo several competing isomerization processes: (i) fast proton ring-walk prior to specific loss of methane; (ii) slow hydrogen exchange between the methyl group and the ring (via 35), giving rise to C-specific but Hunspecific methane loss; and (iii) reversible ring expansion to ions 12, leading to complete carbon and hydrogen scrambling and random loss of methanes. The fractions (i):(ii):(iii) were estimated to be 40:20:40. By comparison of Part I of this review, it may be noted that the variety of isomerization processes in toluenium ions $2\left(\mathrm{C}_{7} \mathrm{H}_{9}{ }^{+}\right)$closely parallels that in $\mathrm{C}_{7} \mathrm{H}_{8}{ }^{+}$ions (162).

The ipso-toluenium ion $i-2$ was suggested as the species which eventually eliminates $\mathrm{CH}_{4}$, a process taking place after substantial hydrogen exchange and skel- 


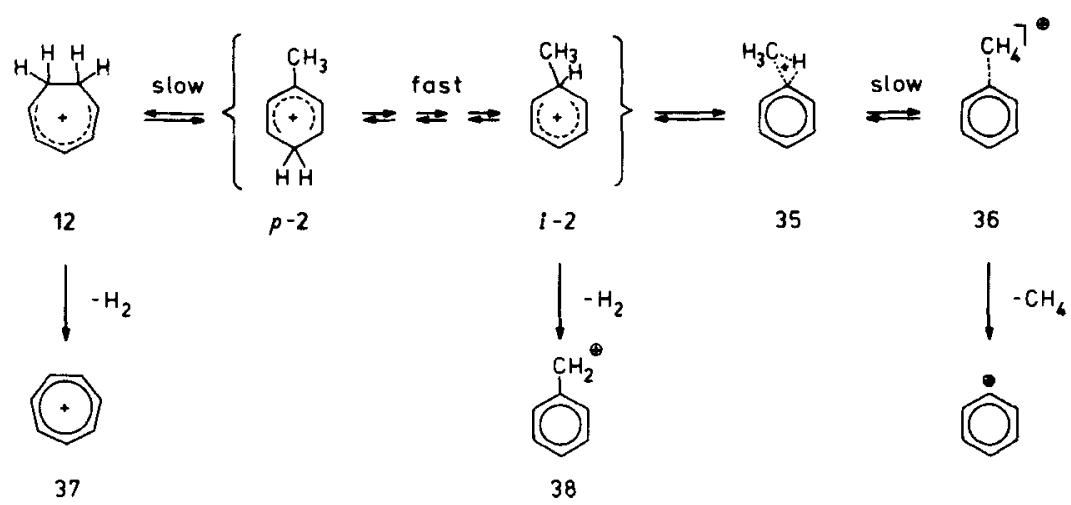

Scheme 12

etal isomerization. The results suggest that $i-2$, instead of or together with 12, may lose $\mathrm{H}_{2}$ in an energy-demanding 1,2-elimination step, to give benzyl ions (38) instead or together with 37.

Kuck et al. $(41,42,95)$ also studied metastable xylenium ions $\mathrm{C}_{8} \mathrm{H}_{11}{ }^{+}$(e.g., 33) in greater detail. These ions eliminate not only $\mathrm{H}_{2}$ and $\mathrm{CH}_{4}$, but also $\mathrm{C}_{2} \mathrm{H}_{4}$ (Scheme 13). The latter fragmentation, in particular, clearly reflects the reversibility of the ring expansion of methylbenzenium ions to the corresponding dihydrotropylium isomers. In the case of the $\mathrm{C}_{8} \mathrm{H}_{11}{ }^{+}$system, recontraction of the seven-membered ring leads preferably to the ethylbenzenium isomers $39, \mathrm{~A}{ }^{13} \mathrm{C}$ - and D-labeling study of ions 33, protonated 7-methylcycloheptatrienes (12), and ions 39 confirms that $\mathrm{C}_{2} \mathrm{H}_{4}$ loss from xylenium ions occurs via the latter isomers. Notably, metastable ions 12 do not eliminate $\mathrm{CH}_{4}$, but fragment much the same as ions 39, suggesting that the ring contraction to 39 is highly preferred over that to 33 or isomeric xylenium ions. It has been suggested from these results that, in general, ring contraction of ( $n$-alkyl)-dihydrotropylium ions to the corresponding [' $(n+1)$ alkyl']benzenium ions is a particularly facile process $(41,95)$.

In contrast to the loss of $\mathrm{C}_{2} \mathrm{H}_{4}$, the elimination of $\mathrm{CH}_{4}$ from xylenium ions is more specific. However, several slow, energy-dependent isomerization reactions precede this fragmentation, including the hydrogen and methyl ring walk, as well as slow exchange between the ring and the methyl hydrogen atoms.

All processes identified in metastable toluenium and xylenium ions can be recognized in other high-energy systems containing $\mathrm{C}_{7} \mathrm{H}_{9}{ }^{+}$ions. For example, ethylbenzene and benzene are formed as minor products during the gas-phase

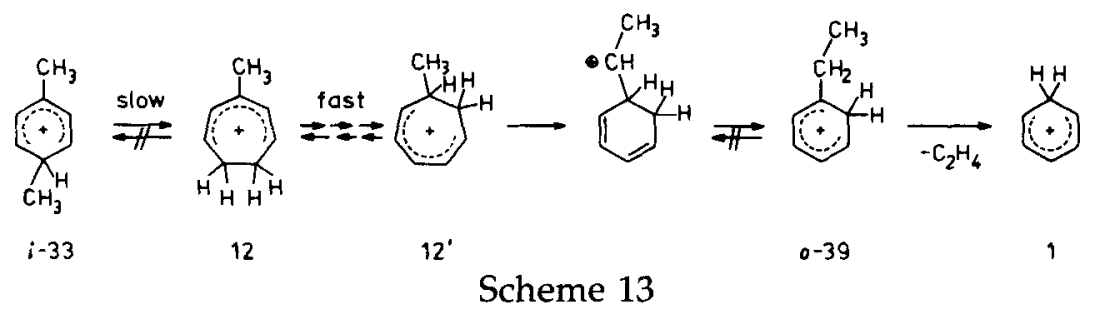


methylation of toluene (152). Exchange between the ring and the methyl hydrogen atoms has been inferred from these experiments as well (152). Morrison et al. $(163,164)$ reacted $\mathrm{CH}_{3}{ }^{+}$ions with benzene and toluene in a triple-stage quadrupole mass spectrometer and found limited hydrogen exchange during the formation of $\mathrm{C}_{6} \mathrm{H}_{5}^{+}$from benzene, and extensive exchange during the formation of $\mathrm{C}_{7} \mathrm{H}_{7}{ }^{+}$ ions, in parallel to some early ICR data (165-167). The role of $\sigma$-complexes in these ion-molecule reactions has been a matter of debate $(163,164,168,169)$. The formation of a $\mathrm{C}^{i p s o}-\mathrm{C}^{\text {methyl }}$ protonated tautomer 35 or a phenylmethonium ion, $\mathrm{C}_{6} \mathrm{H}_{5}-\mathrm{CH}_{4}{ }^{+}$(36) (Scheme 12) as transient species has been invoked (35). These nonclassical isomers correspond to pentacoordinated carbonium ions $(7,170,171)$ which have been identified as a stable (172) or transient (173) species in the gas phase. Liquid-phase rearrangement and fragmentation reaction of alkylbenzenium ions are believed to involve the same nonclassical ions (174).

As an alternative bimolecular entry to toluenium ions, phenyl and tolyl cations have been reacted with methane and other simple alkanes. The main isomerization and fragmentation phenomena observed in these experiments, which were first reported by Speranza et al. (85) and later by Lifshitz et al. (175), are essentially the same as those discussed above. These addition reactions are considerably less exothermic $\left(\Delta H_{r} \simeq-62 \mathrm{kcal} \cdot \mathrm{mol}^{-1}\right)$ than the attack of $\mathrm{CH}_{3}{ }^{+}$on the corresponding arenes (see above). Angelini et al. (86) reacted $\mathrm{CH}_{4}$ with phenyl cations at 20-100 Torr and did not observe the formation of benzyl ions, in contrast to previous ICR results obtained by Speranza et al. (85). With respect to the high activation barrier toward $\mathrm{H}_{2}$ loss $\left(\simeq 48 \mathrm{kcal} \cdot \mathrm{mol}^{-1}\right.$, see above $)$, the collisional stabilization of the toluenium ions leads to complete suppression of the fragmentation reaction, in contrast to the arenium ions formed from $\mathrm{CH}_{3}{ }^{+}$and benzene (and toluene) (152). In a recent ICR study, Ausloos et al. (176) redetermined the rate constants of the reaction of phenyl cations with $\mathrm{H}_{2}, \mathrm{CH}_{4}$, as well as with higher alkanes (see next section), and confirmed the hydrogen randomization during the loss of $\mathrm{H}_{2}$ from the $\mathrm{C}_{7} \mathrm{H}_{9}{ }^{+}$ions formed with $\mathrm{CH}_{4}$. These authors assigned the tropylium rather than benzyl structure to $\mathrm{C}_{7} \mathrm{H}_{7}{ }^{+}$product ions, which in fact does not exclude the reversibility of the skeletal rearrangement and the ipso-toluenium tautomers $i-2$ as the reacting species, as discussed above.

As mentioned above, Field (124) did not find evidence in the standard Cl mass spectra for the ring expansion of toluenium ions, established later for the metastable ions. It is impressive to note, however, that the rapid ring contraction of protonated alkylcycloheptatrienes, formed upon exothermic ethylation of cycloheptatriene in the $\mathrm{Cl}$ source, was proposed by this author. In fact, the mechanism formulated in Scheme 13 on the basis of metastable ion and isotropic labeling experiments accounts perfectly for Field's early suggestions.

\section{Ethyl- and higher alkylbenzenium ions}

The gas-phase chemistry of alkylbenzenium ions with side groups larger than methyl have been studied in a variety of ways. In most cases, these ions were generated by protonation of the neutral alkylbenzenes or by alkylation of the corresponding lower arenes $(4,72,73,78,94,124,177-181)$. Apart from these two 


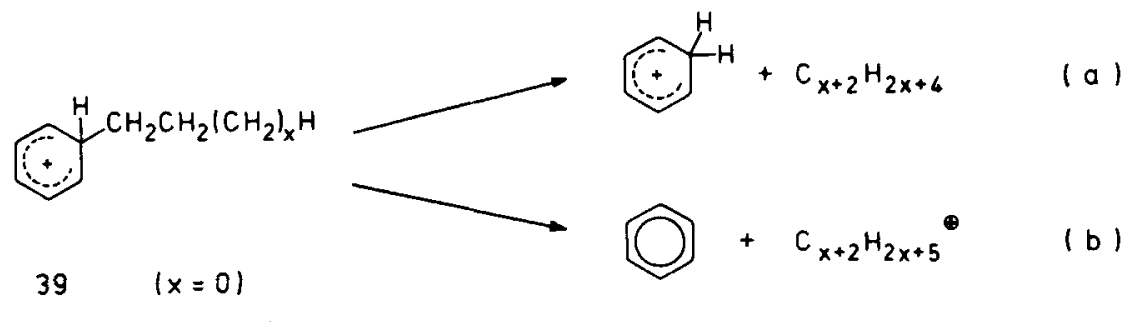

Scheme 14

processes leading to [arene $+\mathrm{H}]^{+}$type ions and their consecutive reactions, the CI mass spectra of alkylbenzenes show ions generated by hydride or alkyde ion abstraction. The chemistry of these species will not be treated in this review except in cases where they may cyclize to benzylbenzenium type ions (see Section VIII.C.2).

As mentioned above, ethylbenzenium ions 39 eliminate $\mathrm{C}_{2} \mathrm{H}_{4}$, rather than $\mathrm{H}_{2}$ or $\mathrm{CH}_{4}$, irrespective of their excitation energy; the latter processes as well as ring expansion to xylenium ions $\mathbf{3 3}$ are almost completely suppressed in metastable ions $39(41,42,95)$. From high-pressure collisional activation experiments, Blom and Munson (94) suggested that the frequency factor for the loss of $\mathrm{H}_{2}$ and $\mathrm{CH}_{4}$ from ions 39 may be particularly low, as compared with the $\mathrm{C}_{2} \mathrm{H}_{4}$ loss, in line with the skeletal rearrangements discussed above. The loss of $\mathrm{C}_{2} \mathrm{H}_{4}$ from 39 is a formal protonolysis of the $\mathrm{C}^{i p s o}-\mathrm{C}^{\alpha}$ bond, with the proton being retained at the benzene rather than at the ethene fragment (Scheme 14). With higher alkyl chains (e.g., 40-42), the corresponding alkene loss (a) decreases in favor of benzene elimination (b), according to the increasing relative proton affinities of the former (see below). The competing loss of alkene and benzene is a general feature of higher alkylbenzenium ions (see, e.g., refs. 71,72,179). In the case of long-chain alkylbenzenium ions and ( $\omega$-phenylalkyl)-benzenium ions (see Section VIII) benzene loss is the exclusive fragmentation path.

The proton affinities of some $n$-alkylbenzenes have been determined by ICR and calculated by $a b$ initio methods $(27,30,74,132)$. In contrast to the stabilization by alkyl groups attached directly to the ring (Section III.B.1; Scheme 10), lengthening of one alkyl chain gives only a minor effect $\left(\Delta \mathrm{PA} \simeq+1 \mathrm{kcal} \cdot \mathrm{mol}^{-1}\right.$ for formation of $40 \mathrm{vs}$. 39), which levels off with $n$-butylbenzene $\left(\Delta P A \simeq+2 \mathrm{kcal} \cdot \mathrm{mol}^{-1}\right)$. Thus, the gas-phase basicities of alkylbenzenes follow the inductive order due to intrinsic polarization effects, in contrast to the reverse, so-called Baker-Nathan effect observed in solution $(8,182)$.

\section{Isomerization and fragmentation}

Wesdemiotis et al. (178) studied the CI ion-source reactions of extensively deuterium and ${ }^{13} \mathrm{C}$-labeled $n$-butyl- and $n$-pentylbenzenes (41 and 42), which are at complete variance with those of the radical-cationic counterparts (183). In particular, hydrogen exchange does not accompany most of the fragmentation reactions, and skeletal rearrangements are completely suppressed. Specific $C-C$ bond heterolysis of the side chain competes with the most energetically favorable cleav- 


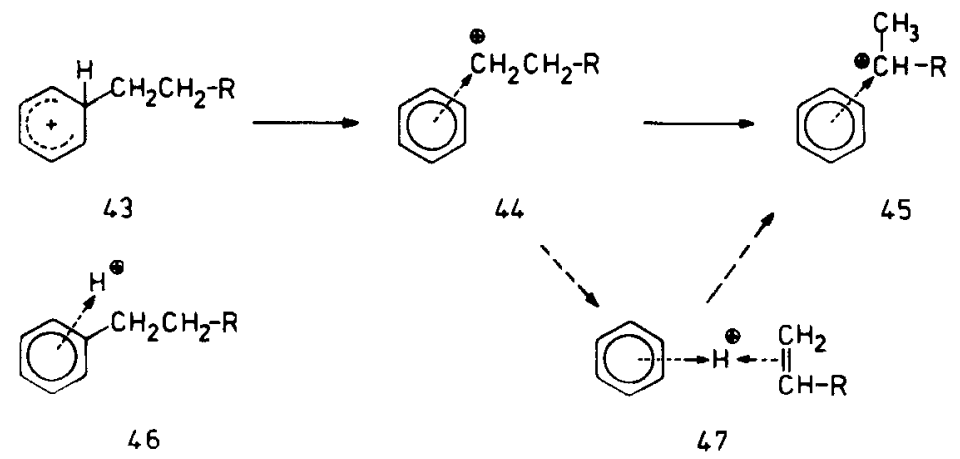

Scheme 15

age of the $\mathrm{C}^{i p s o}{ }_{-} \mathrm{C}^{\alpha}$ bond (Scheme 14). Metastable long-chain alkylbenzenium ions show the same behavior with predominant benzene loss (D. Kuck, unpublished data). The fact that all side-chain bonds except $C^{\alpha}-C^{\beta}$ are cleaved in $n$-alkylbenzenium ions (178) indicates that remote aryl group participation plays an important role, in line with the solvolysis of $\omega$-functionalized alkylbenzenes (184).

Reprotonation of the neutral arene fragment as well as dealkylation of the alkylbenzene substrate by electrophilic attack of the plasma ions $\mathrm{C}_{2} \mathrm{H}_{5}{ }^{+}$and $\mathrm{C}_{3} \mathrm{H}_{5}{ }^{+}$ were also studied $(178,181)$. For example, the degenerate "displacement" of the $\mathrm{C}_{2} \mathrm{H}_{5}$ group in ethylbenzene and para-ethyltoluene by $\mathrm{C}_{2} \mathrm{D}_{5}{ }^{+}$ions is associated with a kinetic isotope effect of $\simeq 2(181)$.

Harrison et al. $(177,179)$ also compared the CI-source fragmentation of paradiethylbenzene and various isomeric alkylbenzenes with particular respect to structure and energy dependence. Fragmentation of the $C^{i p s o}-C^{\alpha}$ bond is particularly dominant with tertiary alkylbenzenes, in line with the facile dealkylation of tert-butylbenzene in solution $(100,101)$. From the study of competitive losses of alkene and benzene and the effect of the exothermicity of protonation, it was concluded that primary alkyl groups rearrange to secondary or tertiary carbenium ions within an intramolecularly formed complex, as shown in Scheme 15.

Elimination of benzene predominates for all $n$ - and isoalkylbenzenes, particularly under relatively mild protonation conditions. By contrast, alkene loss is the major fragmentation path with the corresponding alkyltoluenes $(177,179)$, reflecting not only the increased proton affinity of the toluene portion but also its greater polarizability in the intermediate ion-molecule complex. The alkyl group isomerization during the fragmentation of other gaseous even-electron ions (e.g., $\mathrm{R}$ $\mathrm{CO}^{+}$) has been investigated in detail $(185,186)$.

\section{2. $\sigma$ - and $\pi$ - (and proton-bound) complexes}

The $\sigma$-complex structure is the most stable form of protonated higher alkylbenzenes (e.g., 43, Scheme 15). No evidence has been reported for the existence of $\pi$-complexes bearing the proton in a noncovalent bonded situation, such as shown in formula 46 (cf., 29 in Scheme 9). However, the formation of $\pi$-complexes containing a carbenium ion bonded to the neutral arene (e.g., 44 and 45 ) has 


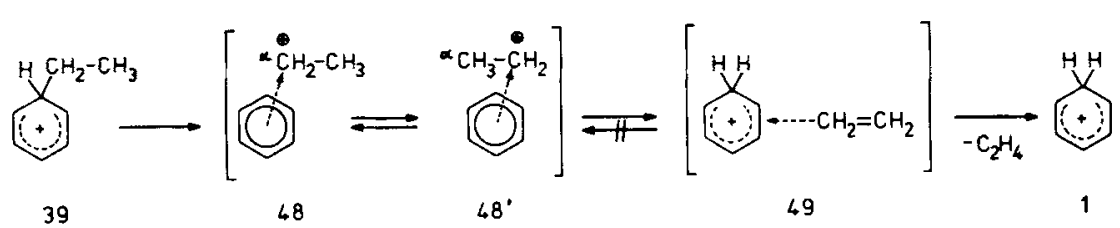

Scheme 16

been demonstrated recently by several groups. Of course, the much higher intrinsic stability of the ionic component $\left(\mathrm{C}_{n} \mathrm{H}_{2 n+1}{ }^{+}\right.$vs. $\left.\mathrm{H}^{+}\right)$diminishes the energy difference between the $\sigma$ - and $\pi$-complex forms (44 vs. $\mathbf{4 3}$ ). Much in contrast, the existence of truly proton-bound olefin pairs (47) appears improbable for the same reason.

Leung and Harrison (180) studied the hydrogen migrations during the CIinduced alkene elimination from ethyl- and $n$-propylbenzenium ions 39 and $\mathbf{4 0}$ by deuterium labelling of the side chain. The migrating hydrogen atoms originate from all positions of the side chain in both cases. The data reflect a slight preference for the $\omega$-positions as donor sites and the interference of energy-dependent isotope effects, but they are notably distinct from those calculated for full randomization of the side-chain hydrogens. In a later report, Herman and Harrison (179) proposed the formation of an incipient alkyl ion solvated by the neutral benzene moiety (Scheme 15). This $\pi$-complex (44) was thought to subsequently isomerize to a proton-bound alkene-benzene pair 47 [a disolvated species (179)], which finally decomposes by eliminating either the alkene or the benzene fragment.

Extended studies on metastable $n$-alkylbenzenium ions have been performed in the Bielefeld laboratory $(41,42,95,187)$ using the El-induced fragmentation of labelled dihydrobenzoic acids (Section II.A.1). Similar results were published recently by Audier (73), and Robin et al. (188), who compared the fragmentation of deuterium-labelled ethylbenzenium ions 39 generated by $\mathrm{CI}\left(\mathrm{H}_{2} \mathrm{O}\right)$ of ethylbenzene and by ion-molecule reactions of benzene with ethyliodide and ethanol. In all cases $(41,42,73,95,187,188)$, the MIKE spectra of ring- $d_{5}$-labelled ethylbenzenium ions confirmed that in fact hydrogen exchange between the side chain and the ring does not occur. Unexpectedly, the regioselectivity of the hydrogen rearrangement during $\mathrm{C}_{2} \mathrm{H}_{4}$ loss in the metastable ethylbenzenium ions is almost the same as that found for the source reaction (180).

A more stringent explanation for the peculiar site selectivity of the hydrogen migration has been envisaged $(73,187)$, much in line with the fragmentation model elaborated for the alkene loss of other ions in the gas phase $(189,190)$. As suggested earlier $(94,179)$, the rate-determining step of the alkene loss from alkylbenzenium ions is indeed the formation of the $\pi$-complex 44. In the case of ethylbenzenium ions 39 (Scheme 16), the incipient $\pi$-complex 48 has been estimated to be slightly $\left(\simeq 4 \mathrm{kcal} \cdot \mathrm{mol}^{-1}\right)$ less stable than the final fragment pair (187). The intermediate protomeric complex $\mathbf{4 9}$ is much more stable, and back-transfer of a proton, and thus proton exchange between the ethene and the benzene fragments, is suppressed. However, despite the possibility that $\mathbf{4 8}$ may be slightly less stable than the final products (see ref. 191), the $\mathrm{C}_{2} \mathrm{H}_{5}{ }^{+}$ion may live long enough to undergo limited hydrogen exchange by $1,2-\mathrm{H}$ shifts $\left(\mathbf{4 8} \rightleftarrows \mathbf{4 8}^{\prime}\right)$ prior to the isomerization 
to complex 49. Hydride shift is extremely facile and rapid in both solvated and gaseous $\mathrm{C}_{2} \mathrm{H}_{5}{ }^{+}$ions and leads to complete randomization in the gas phase $(192,193)$. The activation barrier toward this process is, if not negative $(106,194-196)$, certainly lower than $+5 \mathrm{kcal} \cdot \mathrm{mol}^{-1}(197,198)$. A similar but irreversible $1,2-\mathrm{H}$ shift has been suggested to occur within $\pi$-complexes consisting of $\beta$-phenylethyl ions and benzenes, formed during the fragmentation of protonated 1,2-diphenylethanes [(40), Section VIII].

The mechanisms outlined in Schemes 15 and 16 have been substantiated recently by Holman and Gross (199), and Robin et al. (188), with higher alkylbenzenium ions. If the proton affinities of the arene and the alkene fragments are similar $\left(\leq 5 \mathrm{kcal} \cdot \mathrm{mol}^{-1}\right)$, limited hydrogen exchange may occur between the benzene ring and the alkyl group. Thus, metastable isobutylbenzenium ions exhibit a slow exchange of the tertiary, but not of the primary hydrogen atoms with those at the ring (188), and similar regioselective hydrogen exchange processes have been reported for (2-butyl)benzenium ions [(187); but see ref. 199].

Recently, Holman and Gross (199) studied the isomerization of various alkylbenzenium ions generated from butyl- and pentylbenzenes. Particularly convincing evidence for the transient formation of $\pi$-complexes and their mutual conversion to the corresponding $\sigma$-complexes was obtained from the CID spectrum of protonated 1.1.1-[D $\left.\mathrm{D}_{3}\right]$-2-phenyl-butane, which shows the specific losses of $\mathrm{C}_{2} \mathrm{H}_{6}$ and $\mathrm{C}_{2} \mathrm{H}_{3} \mathrm{D}_{3}$ in a near-unity ratio. Furthermore, the CID spectra of protonated (2-phenyl)- and (3-phenyl)-pentane were found to be identical. Hence an efficient degenerate isomerization of the benzene-solvated secondary alkyl ions was deduced. In line with the evidence reported by other groups, the authors concluded that all high-energy alkylbenzenium ions undergo side-chain isomerization via the corresponding $\pi$-complexes. Again no evidence for a protonbonded complex (cf. 47) was found. $\pi$-complexes may also be formed upon attack of phenyl cations on alkanes such as $\mathrm{C}_{3} \mathrm{H}_{8}$. For example, a thermodynamically controlled isomerization of $n$-propyl-to sec-propylbenzenium ions has been found by Angelini et al. (86).

In another recent communication, Audier et al. (200) reported that low-energy alkylbenzenium ions may expel an alkane if this reaction is energetically more favorable than the alkene or benzene losses. Again, hydrogen exchange between the ring and the butyl group precedes the elimination, which then takes place by regioselective abstraction of a benzylic hydride ion by the $t e r t-\mathrm{C}_{4} \mathrm{H}_{9}{ }^{+}$ion liberated within the $\pi$-complex. An alternative access to the tert-butylarenium ion system was found by reacting tert $-\mathrm{C}_{4} \mathrm{H}_{9}{ }^{+}$ions with para-xylene in the ICR spectrometer (200).

\section{Ethyl-and higher alkylbenzenium ions by alkylation and related reactions}

The alkylation of benzene and substituted benzenes under the conditions of $\mathrm{CI}$ mass spectrometry leads to alkylbenzenium ions with the same reactivity of those ions obtained by protonation or EI-induced fragmentation. Ethylated (alkyl)benzene ions, in particular, have been studied and reported on in a number of the articles discussed in the preceding sections, and most of them will not be 
commented on here. There is, however, much information on the gas-phase chemistry of higher alkylbenzenium ions formed by electrophilic attack of alkyl ions larger than $\mathrm{C}_{2} \mathrm{H}_{5}{ }^{+}$on benzene and alkylbenzenes. Furthermore, ion-molecule reactions of the ionized arenes, or the corresponding phenyl or aryl cations with higher alkanes, have been investigated in much detail (see Section II). Benzenium ions with unsaturated and cyclic alkyl portions will be discussed in the following section.

High-pressure alkylations of arenes have been performed in several laboratories during the past decades. In recent accounts, Cacace $(26,78)$ presented an actual view on the integrated approach to gas-phase ion chemistry. Therefore, the consideration of the enormous material is restricted here to a few aspects. By combining mass spectrometric data with results from radiolysis and nuclear decay $(24,25)$ experiments performed with pressures in the range of $10-750$ Torr (and even to the liquid phase!), valuable information has been obtained on the chemistry of isolated ions. In particular, the effect of thermodynamic and kinetic control, being reflected by the product distributions obtained with low and high pressures, respectively, sheds light on problems concerning isomerizing ionic systems. Thus, isopropylation and tert-butylation of benzene, toluene, and the xylenes (201-206) exhibit remarkable differences in the substrate and regioselectivity of the electrophilic agent. Furthermore, the increased migratory aptitudes of alkyl groups larger than methyl and ethyl at the benzenium ring have become evident (203). As a general feature, para-dialkylbenzenium ions tend to isomerize to the more stable meta isomers under low-pressure conditions, that is, under thermodynamic control (cf., Scheme 11). The use of ortho-xylene has been investigated, in turn, as a trapping agent for isomeric $\mathrm{C}_{4} \mathrm{H}_{9}{ }^{+}$ions $[(206,207)$; see, however, ref. (208)].

Sen Sharma and Kebarle (81) performed temperature-variable HPCI experiments on the methylation and ethylation of benzene, toluene, and isopropylbenzene by dialkylchloronium ions, $\left(\mathrm{CH}_{3}\right)_{2} \mathrm{Cl}^{+}$and $\left(\mathrm{C}_{2} \mathrm{H}_{5}\right)\left(\mathrm{CH}_{3}\right) \mathrm{Cl}^{+}$. Interestingly, ethylation was found to be faster than methylation, and an energy profile involving a $\pi$ - and a solvated $\sigma$-complex was suggested to explain the opposite temperature dependencies observed.

Sen Sharma et al. (209) also investigated the stability of tert-butylbenzenium ions 50 and 51 (Scheme 17). An unusually high negative entropy for the attack of the tert $-\mathrm{C}_{4} \mathrm{H}_{9}{ }^{+}$ion on benzene was measured, which, in comparison to isopropyl and ethylbenzenium ions, contributes considerably to the lability of $\mathbf{5 0}$ toward heterolytic cleavage. Cacace and Ciranni (210) studied the competitive tert-butylation of benzene and toluene upon radiolysis at thermal equilibrium at 720 Torr. In line with the higher stability of $51, k_{\mathrm{tol}} / k_{\mathrm{benz}}$ was found to decrease linearly with increasing temperature but to level off above $100^{\circ} \mathrm{C}$, suggesting backdissociation of the more labile tert-butylbenzenium ion 50 .

The pulsed HPCI study (209) also reports on the occurrence of a transalkylation process, in the course of which a tert $-\mathrm{C}_{4} \mathrm{H}_{9}{ }^{+}$ion is transferred from 51 to a neutral alkylbenzene (Scheme 17). It appears interesting to speculate, in light of the convincing evidence for the role of $\pi$-complex intermediates, whether this transalkylation proceeds via 52 , that is, by an $S_{N} 2$-type mechanism known from the 


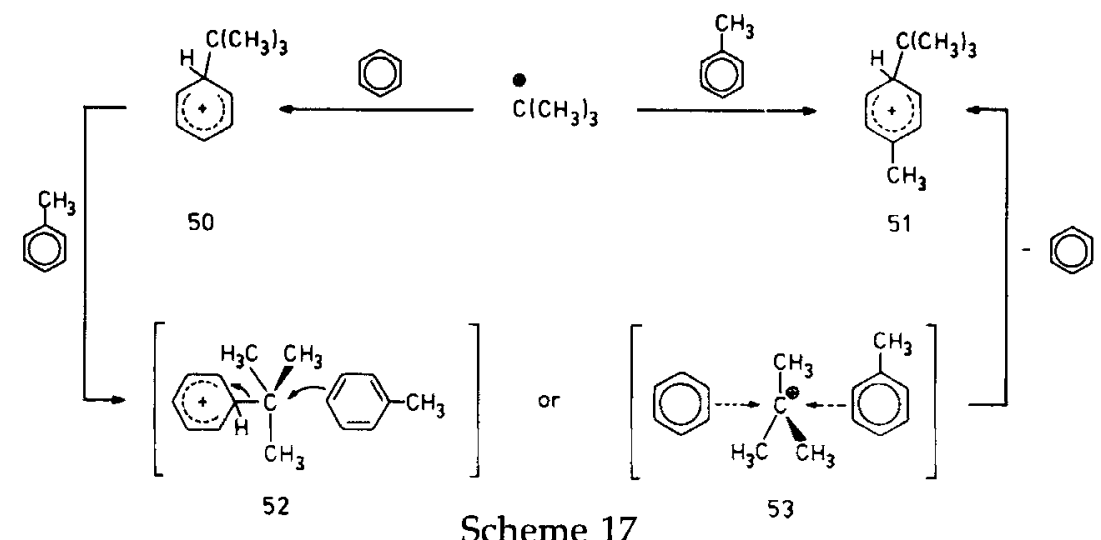

attack of anions on neutral substrates, or via loosely bound ternary $\pi$-complexes 53 (cf., 47, Scheme 15).

Halo- and dihalobenzenes have also been alkylated by sec- $\mathrm{C}_{3} \mathrm{H}_{7}{ }^{+}$ions $(211,212)$. As a general feature observed under kinetic control with halobenzenes but also with anilines (213), anisoles (214), phenols (215), etc. (78), the heteroatomic substituent induces exceptionally high extents of ortho attack by sec- $\mathrm{C}_{3} \mathrm{H}_{7}{ }^{+}$and tert$\mathrm{C}_{4} \mathrm{H}_{9}{ }^{+}$ions (80-90\% in some cases). This effect has been also found with biphenyls [(216); see Section VII.A], but it does not occur with alkyl ions smaller than $\mathrm{C}_{3} \mathrm{H}_{7}{ }^{+}$ (217). The formation of chelated (hydrogen-bonded) $\pi$-complexes has been invoked to explain these results $(78,212,218)$. Alkylation of benzyl chloride does not give enhanced ortho orientation (219). A remarkable 1,2-bromine shift has been found to occur upon iso-propylation of 1-fluoro-4-bromobenzene (212).

Higher gaseous alkylbenzenium ions have been generated by various other ion-molecule reactions, as mentioned in the previous sections for the lower homologs. For example, Bone and Futrell, in an early work (220), showed that propylbenzenium ions are formed by EI of benzene/butadiene mixtures. These ions are also generated by addition of phenyl cations from nuclear decay of tritiated benzene with propane (86) and by reaction of benzene radical cations with 2iodopropane (70-72). Further work on the alkylation of various arenes by sec$\mathrm{C}_{3} \mathrm{H}_{7}{ }^{+}(171,219)$ and sec $-\mathrm{C}_{4} \mathrm{H}_{9}{ }^{+}$ions $(207)$ has been reported.

Wojtyniak and Stone (221) investigated the silylation of benzene and several methylbenzenes by $\mathrm{Si}\left(\mathrm{CH}_{3}\right)_{3}{ }^{+}$ions in the HPCI source. The adduct ions were found to transfer $\mathrm{Si}\left(\mathrm{CH}_{3}\right)_{3}{ }^{+}$, rather than a proton, to various oxygen bases, and the $\pi$-complex structure $\left[\mathrm{C}_{6} \mathrm{H}_{6} \cdot \mathrm{Si}\left(\mathrm{CH}_{3}\right)_{3}{ }^{+}\right]$was deduced from this finding. In contrast (222), nitrogen bases such as $\mathrm{N}\left(\mathrm{C}_{2} \mathrm{H}_{5}\right)_{3}$ do abstract a proton, pointing to the formation of the $\sigma$-complex $\left[\mathrm{C}_{6} \mathrm{H}_{6}-\mathrm{Si}\left(\mathrm{CH}_{3}\right)_{3}\right]^{+}$as the more stable structure. In further studies, Fornarini (223) and Cacace et al. (224) compared the de-tertbutylation and desilylation of tert-butyl- and (trimethylsilyl)toluenes by $\mathrm{CI}$ and under radiolysis. It was suggested that the stabilities of the ipso- and para-silylarenium ions are very similar, in contrast to the corresponding tert-butylbenzenium tautomers (e.g., 50), leading to the much more facile desilylation observed in the experiments. 

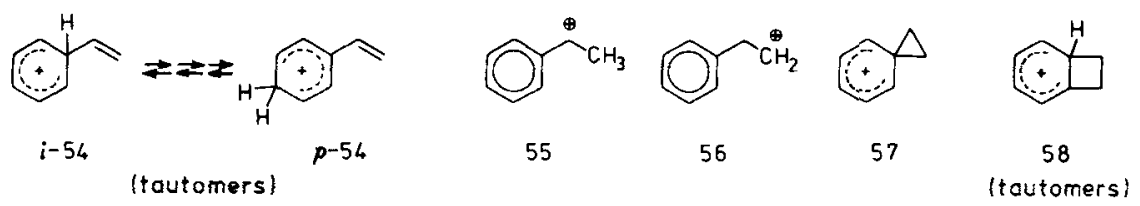

Scheme 18

\section{Benzenium ions with unsaturated and cyclic alkyl groups}

Benzenium ions with alkenyl side chains fall into the group of $\mathrm{C}_{6+} \mathrm{H}_{5+2 n}{ }^{+}$ions. Among the most prominent of these are ions $\mathrm{C}_{8} \mathrm{H}_{9}{ }^{+}$and $\mathrm{C}_{9} \mathrm{H}_{11}{ }^{+}$, several isomers of which have been discussed in Part I, with special respect to methyl-substituted benzyl, tropylium, and phenyl ions. Besides these, a rather complex family of $\mathrm{C}_{8} \mathrm{H}_{9}{ }^{+}$and $\mathrm{C}_{9} \mathrm{H}_{11}{ }^{+}$ions remains, as shown in Schemes 18 and 19. Most of these ions are benzenium ions $(54,57,58$ and $59,63-65,67,69-71$; only the ipso tautomers are shown for the sake of simplicity). Some doubly unsaturated analogs (Scheme 20) have also been studied.

\section{1. $\mathrm{C}_{8} \mathrm{H}_{9}{ }^{+}$ions with benzenium structure}

Attack of vinyl ions on benzene and other arenes has been investigated by Fornarini and Speranza (225) using Fourier transform (FT)ICR mass spectrometry in combination with the nuclear decay technique. The initially formed ring-protonated styrene ions ( $i-54$ to $p-54$ ) were found to expel $\mathrm{H}_{2}$, whereas $\mathrm{C}_{2} \mathrm{H}_{2}$ loss from this $\sigma$-complex to give $\mathrm{C}_{6} \mathrm{H}_{7}{ }^{+}$ions seems unlikely. Deuterium labeling revealed considerable hydrogen rearrangement, but did not allow stringent mechanistic conclusions. At higher pressures, the most stable isomer, $\alpha$-phenylethyl ion 55, was trapped with methanol. Methyltropylium ions, known to be the most thermodynamically stable isomer (Part I), were not found. The alternative access to $\mathrm{C}_{8} \mathrm{H}_{9}{ }^{+}$adduct ions, that is, attack of phenyl cations on ethylene (85), was postulated (225) to give the ethylenebenzenium 57 as the initial product, but the $\mathrm{C}_{8} \mathrm{H}_{9}{ }^{+}$adducts from both sets of ion-molecule reactions showed similar behavior with both techniques employed. Recently, Ausloos et al. (176), however, reported evidence against the simple 1,2-addition of phenyl cations to ethylene to give 57 under ICR conditions. By using ${ }^{13} \mathrm{C}_{2} \mathrm{H}_{4}$ as the neutral reactant, a $70 \%$ fraction of the benzenium ion formed after acetylene loss showed incorporation of one or two ${ }^{13} \mathrm{C}$ atoms, indicating extensive skeletal isomerization by repeated ring expansion and recontraction processes.

Ring-protonated styrenes $\mathbf{5 4}$ are considerably less stable than ion $\mathbf{5 5}$, as shown by Harrison et al. (226). Ion 56 does not represent a local minimum on the $\mathrm{C}_{8} \mathrm{H}_{9}{ }^{+}$ energy hypersurface (see Part I). This stability order corresponds to the local proton affinities of styrene, obtained from correlation with 1 s orbital energies (227) and by $a b$ initio $(107)$ and semiempirical AM1 calculations $(114,228)$. From these studies, the $\beta$ position is considerably $\left(\simeq 8-10 \mathrm{kcal} \cdot \mathrm{mol}^{-1}\right)$ more basic than the para position. Ethylenebenzenium ion 57, identified as a stable cation in solution $(229,230)$, has been studied extensively (see Part I). From radiolysis experiments, Fornarini et al. $(78,231,232)$ considered this ion to be a stable species in the gas 


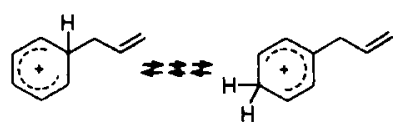

$i-59$ $p-59$ (toutomers)<smiles>CCCc1ccccc1</smiles>

60

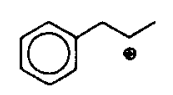

61<smiles>CCCc1ccccc1</smiles>

62

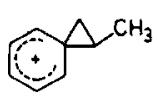

63

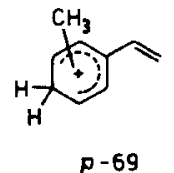

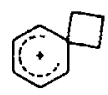

64

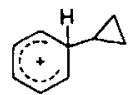

$i-65$

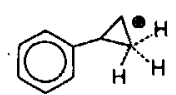

66

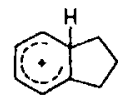

$i-67$

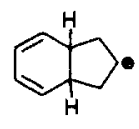

68

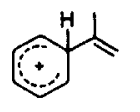

$i-70$<smiles>CC=Cc1ccccc1</smiles>

$i-71$<smiles>CC(C)c1ccccc1</smiles>

72

Scheme 19

phase. It may be noted that $\mathbf{5 7}$ is the simplest benzenium ion without mobile protons, much in contrast to protonated benzocyclobutene 58, which has been postulated by Köppel et al. (233) and McLafferty et al. (234) as one of thirteen stable $\mathrm{C}_{8} \mathrm{H}_{9}{ }^{+}$ions detected by CID mass spectrometry (see Part I). In the light of the above results and the arguments discussed in Part I, it appears tempting to search for evidence of further stable $\mathrm{C}_{8} \mathrm{H}_{9}{ }^{+}$ions, such as the vinylbenzenium ions 54 , in the gas phase.

\section{2. $\mathrm{C}_{9} \mathrm{H}_{11}{ }^{+}$ions with benzenium structure}

The ipso-allylbenzenium ion 59 (Scheme 19) is the prototype ion of the initial products of the gas-phase allylation of alkylbenzenes, occurring frequently under the conditions of $\mathrm{CI}\left(\right.$ iso- $\left.\mathrm{C}_{4} \mathrm{H}_{10}\right)$ mass spectrometry. Therefore, the chemistry of these $\mathrm{C}_{9} \mathrm{H}_{11}{ }^{+}$ions has gained special interest for a long time $(82,83,168,235,236)$. Some global and local proton affinities of $\mathrm{C}_{9} \mathrm{H}_{10}$ arenes have also been studied $(229,237)$.

The ion-molecule reactions of $\mathrm{C}_{3} \mathrm{H}_{5}{ }^{+}$ions with benzene have been investigated in great detail. By using ${ }^{13} \mathrm{C}$-and deuterium labelling, Houriet et al. (236) suggested the formation of two distinct $\mathrm{C}_{9} \mathrm{H}_{11}{ }^{+}$intermediates, viz. 59 and the cycloadduct 68, prior to loss of ethylene. Later, Lay et al. (82) applied FT-ICR and HPCI techniques to identify stable $\mathrm{C}_{3} \mathrm{H}_{5}{ }^{+}$isomers by "gas-phase derivatization" with neutral benzene and phenol. The CID spectra of ions 59 and 70, generated from various model compounds were found to be characteristically distinct and identical to those of the benzene adducts of stable allyl and 2-propenyl ions, respectively. According to its individual CID spectrum, protonated indan (67) was not formed by collisional stabilization, hence the indan type cycloadduct 68 , suggested previously (236), appeared to form as a product of thermodynamic control at low pressures only. 
Protonated methylstyrenes 69, for which probably $\mathrm{PA}^{\text {para }} \simeq \mathrm{PA}^{\beta}$ (see below), exhibit distinct CID spectra. No evidence, however, was obtained for the existence of a third adduct (71), anticipated as the specific derivative of 1-propenyl ions. Rather, the CID spectra suggest that gaseous 1-propenyl ions isomerize to a 2:1 mixture of allyl and 2-propenyl ions prior to derivatization. It seems questionable, however, whether the benzenium ions $\mathbf{7 1}$ and $\mathbf{5 9}$ exist in sufficiently separated energy wells to give distinct CID spectra.

A recent study by Kieu My et al. (83) provided further, independent insight to the $\mathrm{C}_{9} \mathrm{H}_{11}{ }^{+}$system, based on kinetic energy release (T) during the unimolecular loss of $\mathrm{C}_{2} \mathrm{H}_{4}$, as well as on ${ }^{13} \mathrm{C}$ labelling. The $\mathrm{T}$ values allowed to distinguish the $\mathrm{C}_{9} \mathrm{H}_{11}{ }^{+}$ions with linear side chains (59-62, probably including 71 as well, with $\mathrm{T}=22-28 \mathrm{meV})$ and those with branched ones (70 and 72, $\mathrm{T}=42-45 \mathrm{meV}) . \mathrm{A}$ striking result is that protonated indan (67) falls into the latter group ( $T=43$ $\mathrm{meV})$. Therefore, this isomer was excluded as an intermediate during loss of $\mathrm{C}_{2} \mathrm{H}_{4}$ from 59-62. Instead, the ${ }^{13} \mathrm{C}$ labelling data support the formation of 1,3-propylenebenzenium ion 64 as the eventually fragmenting species.

Upon radiolysis of benzene and cyclopropyl bromide in a methyl halide atmosphere [with (cyclo- $\left.\mathrm{C}_{3} \mathrm{H}_{3}\right)-\mathrm{Br}^{+}-\mathrm{CH}_{3}$ as the electrophil], Colosimo and Bucci (238) found allylbenzene rather than indan as the neutral product. The formation of cyclopropylbenzenium 65 as a transient species and its rapid isomerization to 59 were considered. By contrast, Colosimo et al. (87) obtained cyclopropylbenzene and indan as the major products upon electrophilic attack of phenyl cations on cyclopropane at 100-690 Torr. The mechanism proposed includes insertion of the electrophile into the cyclopropane $\mathrm{C}-\mathrm{H}$ and $\mathrm{C}-\mathrm{C}$ bonds, giving the benzenium ions 65 and 64, respectively. The latter ion was assumed to undergo rapid 1,2alkyl shift to give protonated indan (67), as the product of kinetic control. At lower pressures, allyl- and propenylbenzene are formed as the products of thermodynamic control. To explain these findings, cyclopropylbenzenium ions 65 and the nonclassical isomer 66, formed after proton transfer at low pressures (see below) were postulated as intermediates. By using propene instead of cyclopropane, neither indan or cyclopropylbenzene were obtained at all.

Attinà et al. (239) recently reported on the application of the integrated approach to elucidate the chemistry of $\mathrm{C}_{9} \mathrm{H}_{11}{ }^{+}$ions. CI/CID mass spectrometry and radiolysis revealed three groups of stable ions, viz. 60, 72, and 67. The radiolysis results, in particular, are in line with the distinct CID spectra of these ions, excluding skeletal isomerization. Here again, protonated indan seems not to interconvert with the protonated alkenylbenzenes, whereas cyclopropylbenzenium ions do undergo ring opening. On the basis of these findings, it seems likely that ions 67 represent particularly stable isomers of the $\mathrm{C}_{9} \mathrm{H}_{11}{ }^{+}$manifold.

1,2-Propylenebenzenium ions 63 and related benzenium ions have been inferred as intermediates formed upon radiolysis of side-chain functionalized phenylpropanes (232). A further radiolytic study of the $\mathrm{C}_{9} \mathrm{H}_{11}{ }^{+}$system reported on the methylation of styrene by $\left(\mathrm{CH}_{3}\right)_{2} \mathrm{~F}^{+}$ions (240). Competitive attack on the ring, preferentially at the ortho position and at $C^{\beta}$ of the vinyl group was observed.

Galli and Speranza (241) recently reported that the protonation of cyclopropylbenzene occurs on the three-membered ring rather than at $\mathrm{C}^{\text {para }}$. This follows 


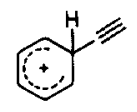

$i-73$
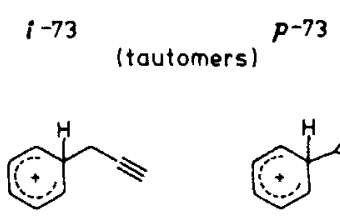

$i-77$
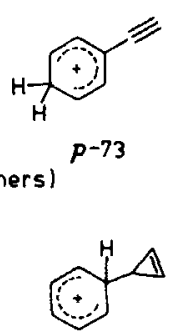

$i-78$

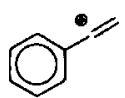

74

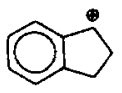

79

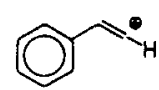

75

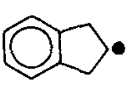

80

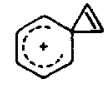

76

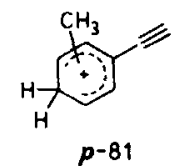

Scheme 20

from a comparison of the similar trends of the proton affinities of cyclopropylbenzene and the cyclopropyltoluenes, on the one hand, and styrene and the methylstyrenes, on the other. In both series, the PA of the meta isomer is lower than that of the ortho and para isomers, in contrast to the xylenes (Section III.B.1) and the methylbiphenyls (Section VII.A). The cyclopropyl group has been inferred to adopt the bisected conformation rather than the perpendicular one.

\section{Alkynylbenzenium and related ions}

Finally, some studies on the doubly unsaturated $\mathrm{C}_{8} \mathrm{H}_{7}{ }^{+}$and $\mathrm{C}_{9} \mathrm{H}_{9}{ }^{+}$ions (Scheme 20) will be mentioned. The relative reactivities of $\mathrm{C}-\mathrm{C}$ double and triple bonds toward electrophils has been reviewed (242). Apeloig et al. (243) reported in detail on the gas-phase chemistry of $\mathrm{C}_{8} \mathrm{H}_{7}{ }^{+}$ions. The $\alpha$-phenylvinyl ion 74 and the vinylenebenzenium ion $\mathbf{7 6}$ were calculated to be the only stable isomers [with $\Delta H_{f}(\mathbf{7 6})-\Delta H_{f}(74) \simeq+16 \mathrm{kcal} \cdot \mathrm{mol}^{-1}$ ], whereas ion 75 does not represent an energy minimum. The acetylenylbenzenium tautomers 73 were not considered. Concerning the ring protonation, Catalán and Yánez (227) estimated the local proton affinities of phenylacetylene to be even more distinct than those of styrene, e.g. , $\mathrm{PA}^{\beta}-\mathrm{PA}^{\mathrm{para}} \simeq+47 \mathrm{kcal} \cdot \mathrm{mol}^{-1}$. On the basis of these data, the benzenium ions 73 should be energetically as unfavorable as ion 75. Marcuzzi et al. (244) recently reported the gas-phase basicities of phenylacetylene and several ringsubstituted derivatives. They were shown to be slightly lower than those of the corresponding styrenes and $\alpha$-methylstyrenes.

Similar to the gas-phase derivatization of $\mathrm{C}_{3} \mathrm{H}_{5}{ }^{+}$ions, isomeric $\mathrm{C}_{3} \mathrm{H}_{3}{ }^{+}$ions have been reacted with benzene to discriminate between their structures. Thus, Ausloos and Lias (245) proposed that the propargyl ion $\left(\mathrm{HC} \equiv \mathrm{C}--\mathrm{CH}_{2}{ }^{+}\right)$forms transient $\mathrm{C}_{9} \mathrm{H}_{9}{ }^{+}$species 77 which eliminates $\mathrm{C}_{2} \mathrm{H}_{2}$ to give $\mathrm{C}_{7} \mathrm{H}_{7}+$ ions, while the cyclopropenium ion, as a $2 \pi$-electron arene, is unreactive. Hence, no information seems available on the corresponding adduct ions 78 . The local proton affinities of indene at $C^{2}$ and $C^{3}$ have been computed by the AM1 method (228); ion 79 is predicted to be more stable than ion 80 by $\simeq 19 \mathrm{kcal} \cdot \mathrm{mol}^{-1}$. Recently Crestoni and Fornarini (240) studied the methylation of phenylacetylene by $\left(\mathrm{CH}_{3}\right)_{2} \mathrm{~F}^{+}$ions upon $\mathrm{CI}$ and, in particular, upon radiolysis. The latter approach revealed competitive electrophilic attack at $C^{\beta}$ of the ethynyl group and at the 
ring to give, initially, benzenium ions 81. Some alkynylbenzenium ions with two benzene rings will be discussed in Section VIII.B.3.

The overall mechanistic picture of the gas-phase chemistry of protonated unsaturated alkylbenzenes and related species has grown much with detailed information during the last decade. Some discrepancies have become evident, in particular with the $\mathrm{C}_{9} \mathrm{H}_{11}{ }^{+}$system, and important experiments are awaited.

\section{PROTONATED BIPHENYLS AND HETEROSUBSTITUTED BENZENIUM IONS}

\section{A. Protonated biphenyls}

Not much is known about the gas-phase chemistry of protonated biphenyls (phenylbenzenium ions). The proton affinity of the parent hydrocarbon is almost identical to that of higher (mono)alkylbenzenes [196 kcal $\left.\cdot \mathrm{mol}^{-1}(30)\right]$, suggesting that no special stabilizing effect, say by proton bridging between the rings, occurs. The PAs of the isomeric monomethylbiphenyls, 82, have been determined recently (241), and were found to be closely in line with the trend expected from the simpler methylbenzenes, i.e., $\operatorname{PA}(m-82)>\operatorname{PA}(p-82) \simeq \operatorname{PA}(0-82)$.

Cacace et al. (216) investigated the gas-phase alkylation of biphenyl and various methyl derivatives. Extensive comparison of isomeric ions was performed by CID spectrometry. Electrophilic attack of $\left(\mathrm{CH}_{3}\right)_{2} \mathrm{~F}^{+}$under radiolytic conditions gives rise to high fractions of ortho-methylated products, indicating a precomplexation of the reagent by both phenyl rings similar to the alkylation of heterosubstituted arenes [see Section II.C.3, (78)].

Wolfschütz and Schwarz (246) compared the CID spectra of protonated biphenyl $\left(\mathrm{C}_{12} \mathrm{H}_{11}{ }^{+}\right)$, generated by $\mathrm{CI}\left(\mathrm{CH}_{4}\right)$ and $\mathrm{CI}\left(\mathrm{H}_{2}\right)$, and of the $[2 \mathrm{M}-\mathrm{H}]^{+}$ion formed by ion-molecule reaction of benzene. The latter ion is particularly interesting as one of a series of ions formed by di- and oligomerization processes of benzene under electron impact. It was concluded that the "dimerization" process produces the phenylbenzenium structure rather than a ring-opened phenylhexatriene or phenylhexenyne isomer, as suggested by Harris et al. (247).

Phenylbenzenium ions were formed during $\mathrm{H} / \mathrm{D}$ exchange in the $\mathrm{CI}\left(\mathrm{D}_{2} \mathrm{O}\right)$ source [(137), see next section].

\section{B. Substituent effects in intermolecular proton transfer involving benzenium ions}

Proton exchange at benzene and substituted benzenes has been of much interest over the years. Electron-donating substituents enhance the overall proton affinities of the benzene ring, but may also contribute by acting directly as the proton acceptor. There is a lack of quantitative experimental studies concerning the local proton affinities of heterofunctionalized benzenes, but several computational studies have been published concerning relative stabilities of heterosubstituted arenium ions. 


\section{Intermolecular hydrogen deuterium exchange with heteroacids}

Qualitative experimental evidence on this problem was provided from $H / D$ exchange in substituted benzenes in the $\mathrm{CI}$ source using polar deuterated reagent gases such as $\mathrm{D}_{2} \mathrm{O}, \mathrm{ND}_{3}$, and $\mathrm{O}$-deuterated alcohols (ROD). Martinsen and Buttrill (137) found significantly different degrees of deuterium incorporation in the $\mathrm{CI}\left(\mathrm{D}_{2} \mathrm{O}\right)$ mass spectra of benzene, some methylbenzenes, and biphenyl. For example, H/D exchange is fast with ortho- and para-xylene but slow with meta-xylene, mesitylene, and biphenyl. Heterosubstituted benzenes undergo either protonation on the ring or at the substituent. Hunt and Sethi (138) confirmed and extended these observations and showed in addition that the extent of $H / D$ exchange at the ring positions is enhanced with increasing basicities of the reactant gases $\left(D_{2} \mathrm{O}<\right.$ ROD $<\mathrm{ND}_{3}$ ). This holds in particular for highly basic arenes such as phenols and anilines, showing that the protonation exothermicity affects the lifetime of the ion-molecule complex and hence the efficiency of the H/D exchange (see also ref. 18). A previous ICR work by Freiser et al. (139) also demonstrated the substrate and site specificity of the H/D exchange of various substituted benzenes. In particular, anisole was found to protonate on the para position of the ring. In general, only the most basic ring sites act as proton acceptor and donor during the H/D exchange.

Ausloos and Lias (248) investigated the efficiency of the thermoneutral proton exchange between heteroacids such as deuterated alcohols, mercaptans, etc. ([M $+\mathrm{DJ}^{+}$) with simple arenes by using ICR spectrometry. The most efficient isotope exchange was found in those cases for which the proton transfer within the complex, namely $\left\langle[\mathrm{M}+\mathrm{D}]^{+} \cdot\right.$ arene $\rangle \rightarrow\left\langle\mathrm{M} \cdot[\text { arene }+\mathrm{D})^{+}\right\rangle$is exothermic. These authors also reported the rates of the degenerate proton transfer between benzenium and toluenium ions (see Section VIII.E).

\section{Proton affinities and electrophilic attack at the ring and the substituent}

Lau and Kebarle (74) reported the gas-phase basicities and proton affinities of a series of monosubstituted benzenes $\mathrm{C}_{6} \mathrm{H}_{5} \mathrm{X}$, which range from $183 \mathrm{kcal} \cdot \mathrm{mol}^{-1}$ for fluorobenzene to $209 \mathrm{kcal} \cdot \mathrm{mol}^{-1}$ for aniline. From a correlation with ab initio values reported by McKelvey et al. (249), all arenes, except those with $\mathrm{X}=\mathrm{CHO}$, $\mathrm{CN}$, and $\mathrm{NO}_{2}$, apparently prefer to protonate at the ring. De Frees et al. (250) showed in a combined ICR and $a b$ initio study that this also holds for phenol, whereas ring protonation of aniline (251-253) is a somewhat less favorable than protonation at the amino group. CID spectrometry of protonated phenol and aniline, reported by Wood et al. (254), confirmed that the hydroxybenzenium structure is formed exclusively, but it suggested that the aminobenzenium ion is also formed predominantly.

The thermodynamics of protonated halobenzenes have been determined (26$29,143,255)$. In the case of fluorobenzenes, ring protonation is by far more favorable than protonation of fluorine, similar to protonation in solution (256), but locking of the incoming proton at the substituent atom has been suggested $(257,258)$ from the temperature-dependent $\mathrm{CI}\left(\mathrm{CH}_{4}\right) / \mathrm{CID}$ as well as from ICR mass spec- 
trometry (259), in line with the behavior of fluorobenzenes upon gas-phase protonation (90-92). The energetics of the proton ring walk on protonated fluorobenzene (260) and anisole (261) have been computed.

Methyl and ethyl cation attack on heterosubstituted benzenes has also been investigated. According to CID analysis $(255,262)$, phenol is alkylated predominantly at the ring, whereas aniline and thiophenol undergo prevailing alkylation of the heteroatom. Charge stripping mass spectrometry has also been applied to locate the site of cationization (263). A previous CID (264) study showed that protonation, ethylation, and allylation of nitrobenzenes occur predominantly at the nitro group. Noteworthily, under kinetically controlled conditions, alkylation of phenol occurs largely on the substituent (214), in contrast to aniline (212).

\section{Protonated Di-, Tri-, and Tetraphenylalkanes, ( $\omega$-Phenylalkyl)benzenium Ions}

Contrary to the protonated biphenyls, the gas-phase chemistry of protonated diarylalkanes has been investigated in much more detail. These studies also included alkylbenzenes with more than two benzene rings and were designed to explore the intramolecular hydrogen transfer between two (or more) benzene rings within the same molecular entity.

The gas-phase chemistry of protonated di- or oligophenylalkanes is greatly different from that of the corresponding radical cations. As pointed out in Part $\mathrm{I}$, the fragmentation of ionized diphenylmethane is largely dominated by skeletal rearrangement including $\mathrm{C}-\mathrm{C}$ bond formation between the rings; ionized 1,2diphenylalkanes cleanly undergo cleavage of the central $\mathrm{C}-\mathrm{C}$ bond. The characteristic feature of the radical cations of 1,3-diphenylpropane (16, Scheme 4) and of the closely related 2-benzylindans (e.g., 18), is a relatively fast and highly regiospecific hydrogen exchange between opposite benzylic and ortho positions, followed by formation of $\mathrm{C}_{7} \mathrm{H}_{7}{ }^{+}$and $\mathrm{C}_{7} \mathrm{H}_{8}{ }^{+}$ions (265-268). Long-chain homologs of 16 react less specifically (269). In favorable cases $(62,268,270,271)$, the elimination of an intact arene is a characteristic pathway, induced by intramolecular proton transfer to the ipso position of the leaving ring (Scheme 4).

\section{A. Fragmentation}

Protonated diphenylalkanes 7 [Scheme 21 (a)] and related species all show the arene loss as by far the predominant or even exclusive primary fragmentation reaction. The first example was published in 1979 (34), using the EI approach to generate protonated 1,2-diphenylethane $83(X=Y=H)$ and 1,3-diphenylpropane 86. Later, both EI and CI techniques were used to study this family of unusually large alkylbenzenium ions (36-39,84,272-275). The predominance of arene loss was found for both short- and long-lived (metastable) ions throughout the whole series of protonated di- and oligophenylalkanes with saturated open-chain or cyclic alkane units between the rings. There is evidence that this process occurs either by $1,2-\mathrm{H}$ shifts or by remote aryl participation [Scheme 21 (b), (c)], to stabilize the incipient carbenium ion. Another rearrangement scheme during the benzene loss is 1,2-C shift (see Section VIII.D.2). The formation of a $\alpha$-phenylethyl ions 


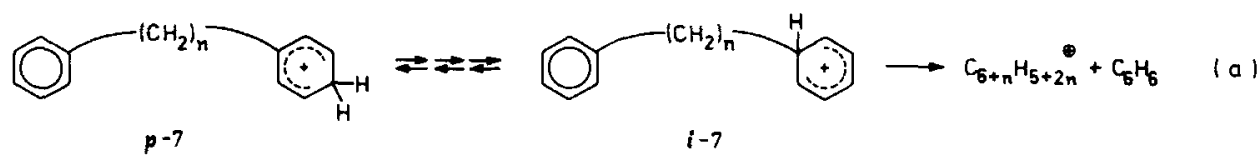

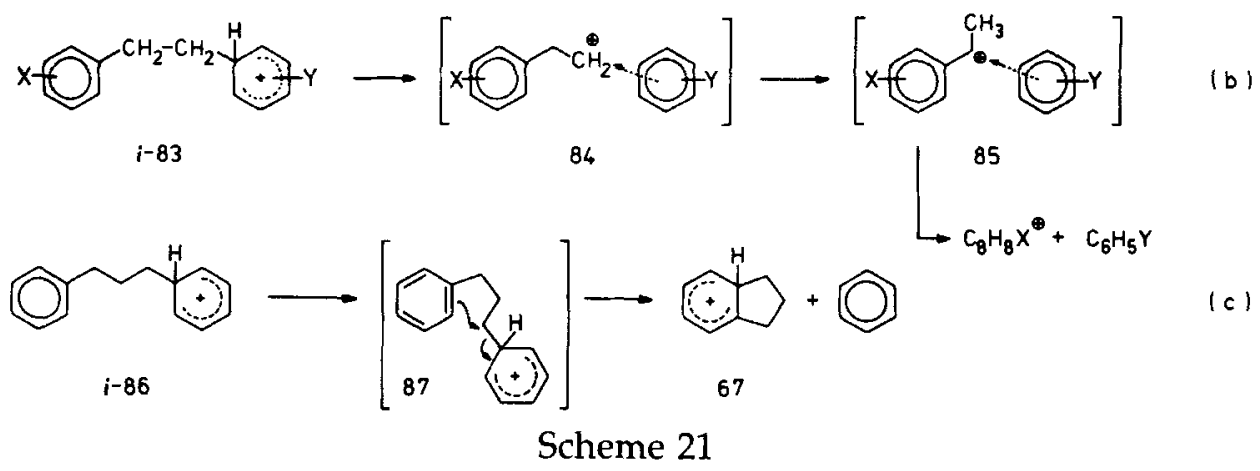

(55; Scheme 18) is indicated from appearance energy measurements on the formation and fragmentation of various substituted ( $\beta$-phenylethyl)-benzenium ions $83\left[X, Y=\mathrm{CH}_{3}\right.$ and $\left.\mathrm{OCH}_{3}(40)\right]$. The 1,2-H shift has been inferred from the substituent effects to occur in a series of unimolecularly formed ion-molecule complexes (e.g., 84). The cyclization of the ionic fragment during the decomposition, via 87, of higher $\omega$-(phenylalkyl)-benzenium ions (e.g., $86 \rightarrow 67$ ) is strongly corroborated by the consecutive fragmentation of protonated oligophenylalkanes (see Section VIII.D.2).

\section{B. Interannular and intraannular proton transfer reactions}

\section{Protonated $\alpha$, $\omega$-diarylethanes and higher homologs and analogs}

Protonated $\alpha, \omega$-diphenylalkanes ( $\omega$-phenylalkylbenzenium ions) with two to twenty methylene units in the aliphatic chain undergo a fast proton transfer between the rings (Scheme 22). In metastable ions this leads to a complete equilibration of the eleven hydrogen atoms at the aromatic rings within some microseconds. By contrast to the corresponding radical cations, the hydrogen atoms of the polymethylene chain are not involved in this process. Assuming a fast and complete equilibration within the temporarily formed benzenium ring, in other words, intraannular proton exchange $[p-7 \rightleftarrows m-7 \rightleftarrows 0-7 \rightleftarrows i-7$, Scheme 21 (a)], at least 20 interannular proton transfer steps are necessary to achieve a near-random proton distribution over the rings (34). Later, kinetic model calculations corroborated this estimation, and the rate constants for the interannular proton transfer were estimated to be $k_{\mathrm{H}}>1 \cdot 10^{6} \mathrm{~s}^{-1}(36,39)$.

Substituent effects on the interannular proton exchange were also studied, to probe the effect of different proton affinities of the benzene rings. For example, 2-[(para-anisyl)ethyl]-benzenium ions $83\left(\mathrm{X}=p-\mathrm{OCH}_{3}, \mathrm{Y}=\mathrm{H}\right)$, generated by EIinduced fragmentation of the corresponding dihydrobenzoic acids, exhibit full proton equilibration prior to the competing losses of benzene and anisole (37), 


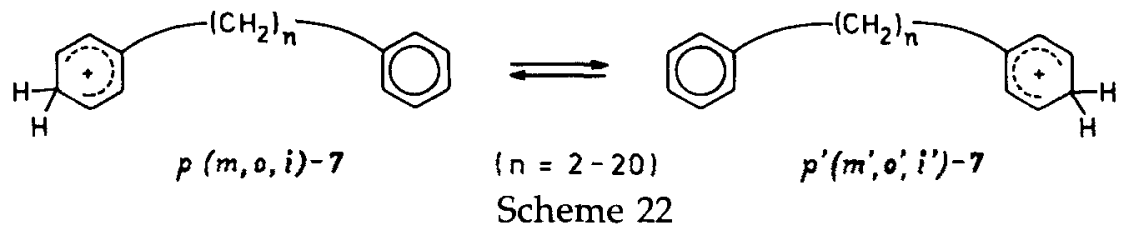

as do the isomeric protonated 1-phenyl-2-tolylethanes $83\left[\mathrm{X}=0-, m-\right.$, and $p-\mathrm{CH}_{3}$ (D. Kuck, to be published)]. Hence, PA differences as large as $\simeq 15 \mathrm{kcal} \cdot \mathrm{mol}^{-1}$ do not suppress the fast proton transfer. With higher PA differences, for example, in the corresponding [( $\omega$-dimethylanilino)ethyl]-and [ $\omega$-pyridyl)ethyl]benzenium ions, however, proton transfer from the benzenium moiety to the more basic ring becomes largely irreversible (37).

\section{Stereocontrol in protonated 1,4-bis-( $\omega$-phenylalkyl)cyclohexanes}

Recently, Kuck et al. (274) showed that introduction of a cyclohexane ring into the aliphatic link between the protonated and the neutral benzene ring exerts a distinct stereocontrol of the rate of the intrannular proton transfer. Whereas protonated cis-1,4-dibenzylcyclohexane (88, Scheme 23) undergoes complete equilibration of the aromatic hydrogen atoms on the metastable ions' time scale, the trans isomer 89 exhibits a slow exchange and a pronounced kinetic isotope effect (see Section VIII.C.4). Obviously, the cyclohexane ring in ions 89 has to adopt energetically unfavorable twist or boat conformations to permit the proton transfer. The doubly-homologuous protonated trans-bis ( $\beta$-phenylethyl)cyclohexane 90 was found to represent an intermediate case with fast but clearly incomplete proton equilibration. Thus, the interannular proton transfer in ions $\mathbf{8 8 - 9 0}$ is slower than in open-chain protonated $\alpha, \omega$-diphenylalkanes $7(n>1)$ but higher than in protonated diphenylmethane $7(n=1)(\equiv 94$, Section VIII.C.4). Further examples of fast intrannular proton transfer will be discussed in Section VIII.D.1.

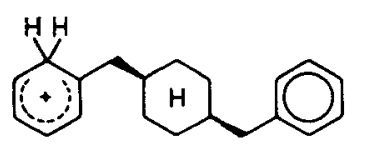

88<smiles>C1=CC=CC(C[C@H]2CC[C@H](Cc3ccccc3)CC2)C=1</smiles>

89

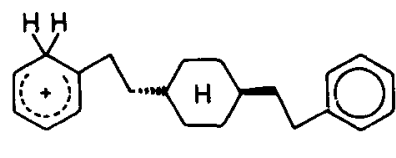

90
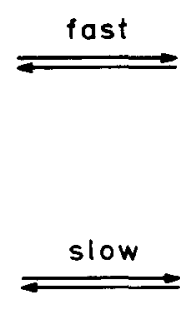

'medium'

Scheme 23

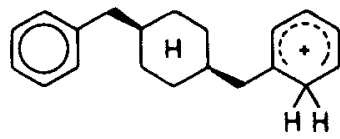

$88^{\circ}$

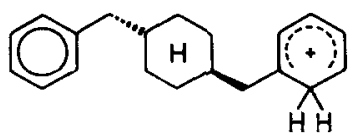

$89^{\circ}$

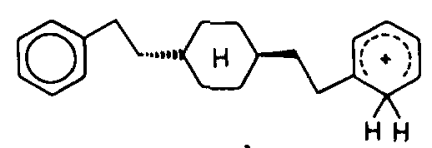

$90^{\prime}$ 


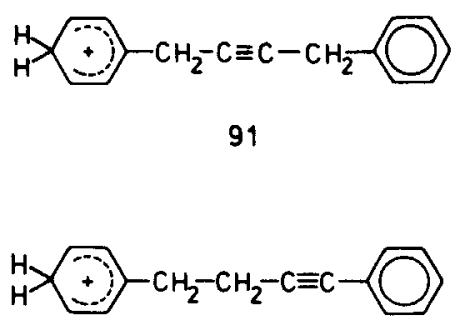

92

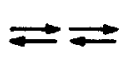

$$
\text { (1) }
$$$$
{ }_{H}^{H}+\mathrm{CH}_{2}-\mathrm{C} \equiv \mathrm{C}-O
$$

93

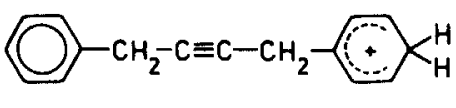

$91^{\circ}$

Scheme 24

\section{Protonated $\alpha, \omega$-diarylalkynes}

As discussed in Section VI.D.3, acetylenic triple bonds are much more basic than the $\pi$-system of an alkylated benzene. Therefore, protonated $\alpha, \omega$-diphenylalkynes $(36,38,39)$ exhibit a participation of the basic, unsaturated link in the interannular proton transfer. Starting with ring-protonated 1,4-diphenyl-2-butyne 91, generated by EI-induced fragmentation, the interannular proton exchange occurs to a limited extent, probably mediated by the sticky, albeit very basic, 2butyne-1,4-diyl link. However, isomeric ions 91 and 92 (Scheme 24) do not interconvert. Ring-protonated 1,3-diphenylpropyne 93, bearing the extra proton at the 3-phenyl group, shows participation of the propyne hydrogen atoms, leading to extended albeit incomplete all-hydrogen scrambling. As a peculiarity, metastable ions 93 expel predominantly a $\mathrm{CH}_{3} \bullet$ radical, as a consequence of extensive skeletal isomerization by reversible ring closure to indanyl-type ions (cf., 79, Scheme 20).

\section{Protonated diphenylmethanes}

Protonated diphenylmethane (benzylbenzenium ions) 94 deserves a special discussion for two reasons. First, ions 94 represent the prototype ( $\omega$-phenylalkyl)benzenium ions which undergo a slow ring-to-ring proton exchange, allowing recognition of the independent occurrence of the inter- and intraannular proton transfer processes (see below). Second, a large number of papers report on the intermolecular benzylation of arenes, under various conditions (Scheme 25). As shown in Part $\mathrm{I}$, this reaction has been widely used as a probe for the benzylium structure in a mixture of $\mathrm{C}_{7} \mathrm{H}_{7}{ }^{+}$ions. The initial product is a methylated benzylbenzenium ion (95), which fragments by loss of one of the arene units, giving rise, in toto, to the transfer of a $\mathrm{CH}$ (methine) unit from the benzyl ion to the neutral arene (a process often called "methylene transfer").

\section{Intermolecular benzylation of arenes}

The formation of "dimeric" species such as $\mathrm{C}_{14} \mathrm{H}_{15}{ }^{+}$was observed by $\mathrm{CI}$ mass spectrometry $(276,277)$ and radiolysis $(278-281)$ of toluene, meta-xylene, and ethylbenzene. These early reports show that the initial product of benzylation is a 

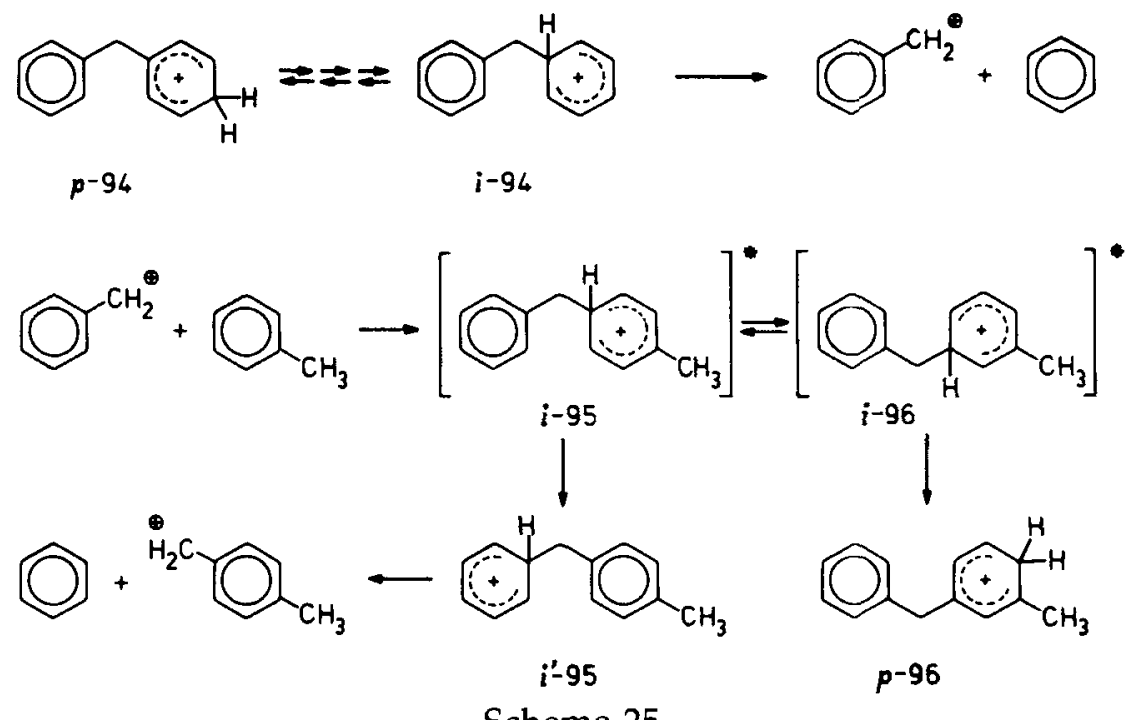

Scheme 25

protonated diphenylmethane derivative ( $i-95$, Scheme 25$)$, which can be stabilized and deprotonated at higher pressures. At lower pressures, thermodynamic control leads to predominant formation of meta benzylation products, due to the higher stability of the corresponding benzenium intermediate (e.g., p-96) (280).

Later, Shen et al. (282) suggested a mechanism for the methylene transfer reaction from benzyl ions to toluene on the basis of ICR measurements with deuterium-labelled reactants. No evidence was found for hydrogen exchange within the short-lived $\mathrm{C}_{14} \mathrm{H}_{15}{ }^{+}$adduct ions, suggesting a four-membered transition state $\left(i-95 \rightarrow i^{\prime}-95\right)$. Photodissociation studies by Dunbar $(283,284)$ and ICR studies by Jackson, Lias, and Ausloos (285-287) corroborated the specificity of the methylene transfer reaction. These authors (286) also reported on the benzylation reaction of several other methyl- and higher alkylbenzenes as well as to halotoluenes and benzyl halides, including the determination of the rate constants (see also ref. 288).

In another study, Sen Sharma and Kebarle (288) stabilized the $\mathrm{C}_{14} \mathrm{H}_{15}{ }^{+}$adduct under HPCI conditions. The activation energy of the consecutive benzene loss was determined to be $32.5 \mathrm{kcal} \cdot \mathrm{mol}^{-1}$. This is considerably higher than its endothermicity $\left(\Delta H_{r} \simeq 23 \mathrm{kcal} \cdot \mathrm{mol}^{-1}\right)$ and slightly higher than that of the reverse reaction ( $\Delta H_{r} \simeq 30 \mathrm{kcal} \cdot \mathrm{mol}^{-1}$; based on data from ref. 30). Therefore, the proton transfer step $\left(i-95 \rightleftarrows i^{\prime}-95^{\prime}\right)$ should be the energy determining one, in line with the finding (287) that hydrogen exchange is not significant in the products of the methylene transfer reaction. Furthermore, the parent ion $\mathbf{9 4}$ shows, in fact, an extremely slow interannular proton exchange, as will be shown below.

\section{Proton exchange in metastable benzylbenzenium ions}

Notably, no report has appeared concerning with the interannular proton transfer in metastable benzyltoluenium ions (95 or 96). Protonated diphenylmethane 


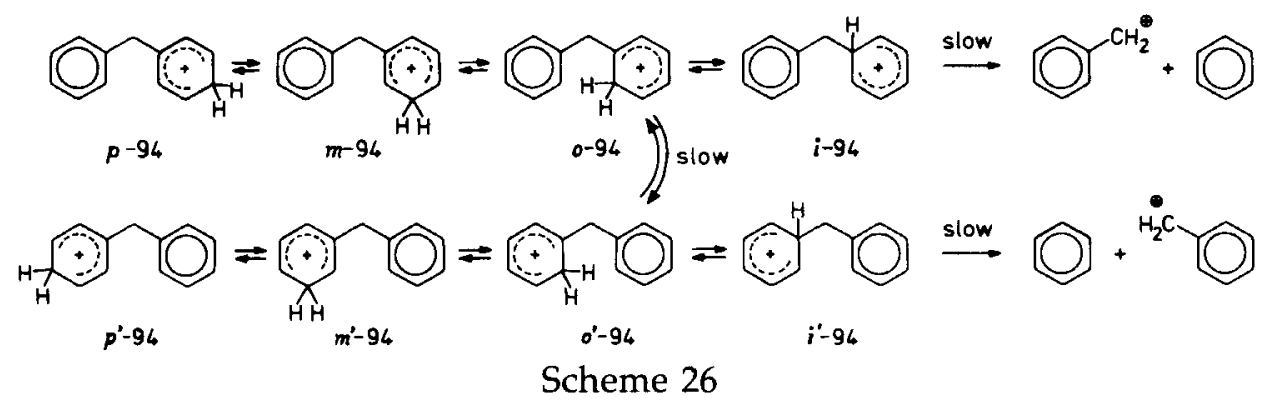

94, however, has been studied by deuterium labelling (84). In contrast to the higher homologs, the interannular proton exchange in ions 94 is relatively slow $\left(k_{H} \simeq 5 \times 10^{5} \mathrm{~s}^{-1}\right)$ and competes with the loss of benzene. As a consequence, a kinetic isotope effect $\left(k_{H} / k_{D} \simeq 5\right)$ operates during the proton transfer. From the similar behavior of two regiospecifically labeled isotopomers $\left(\left[2,4,6-\mathrm{D}_{3}\right]-94\right.$ and $\left.\left[3,4,5-D_{3}\right]-94\right)$, the intraannular hydrogen exchange was shown to be fast, thus equilibrating the six hydrogens in the temporarily protonated benzenium portion prior to the interannular proton transfer.

The usual behavior of benzylbenzenium ions was attributed to steric restrictions to the ring-to-ring proton transfer. It was suggested that, in contrast to the higher homologs, only the ortho positions can act as the proton donor and acceptor sites, yet assuming a nonlinear transition-state geometry for the proton transfer reaction. A proton jump from the ipso positions $\left(i-94 \rightleftarrows i^{\prime}-94\right)$, suggested earlier (95) from the intermolecular benzylation experiments (see above), seems impossible because of highly bent transition states. From the study of metastable ions 94 (84), the energy barrier for interannular proton transfer has been estimated to be $>15 \mathrm{kcal} \cdot \mathrm{mol}^{-1}$, in fair agreement with the thermochemistry of the benzylation of toluene discussed above (288).

Slow interannular proton exchange has also been found (D. Kuck, manuscript in preparation) in the $[\mathrm{M}-\mathrm{H}]^{+}$ions of $\alpha, \omega$-diphenylalkanes (e.g., 97) and related alkylbenzenes, formed by hydride abstraction from the benzylic positions (Scheme 27). Cyclization leads to protonated 1-phenylbenzocycloalkanes (e.g., 99), which again represent protonated diphenylmethanes with characteristically slow proton transfer between the aromatic nuclei.

\section{Further gas-phase benzylation reactions of arenes}

Intramolecular benzylation of aromatic nuclei occurs in benzyl ethers upon CI mass spectrometry. Kingston et al. (289-291) investigated the isomerization and fragmentation of protonated dibenzyl and benzyl $\beta$-phenylethyl ethers upon $\mathrm{CI}$ mass spectrometry. No ring-to-ring proton transfer was observed, obviously due to the predominant protonation at the ether functionality. Indeed, the major fragmentation starts by $O$-protonation, which activates the adjacent benzyl group to undergo an intramolecular electrophilic attack at the second arene nucleus, yielding transient benzylbenzenium-type ions. An analogus transfer of the $\beta$ - 


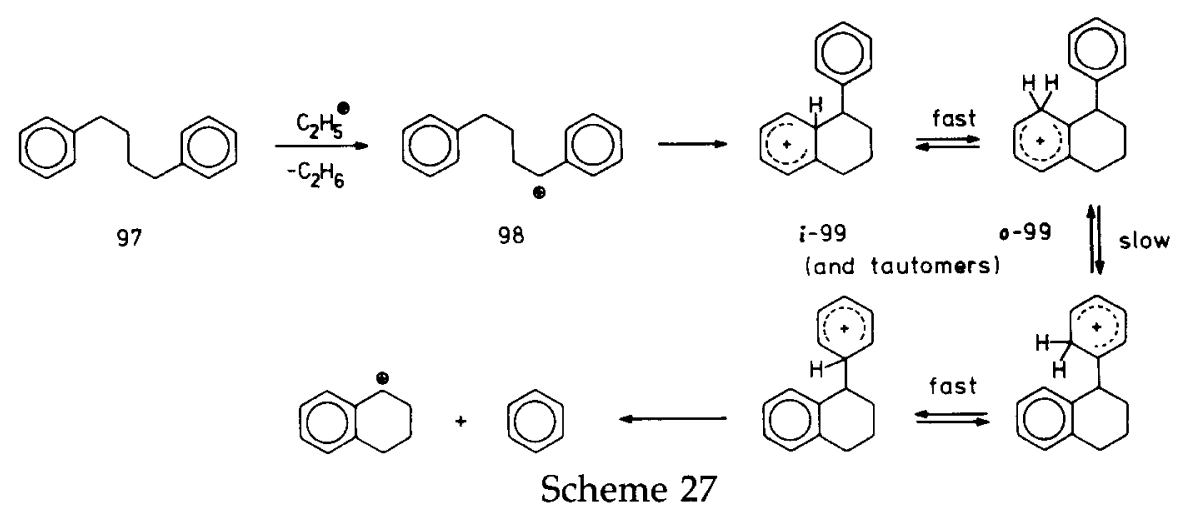

phenylethyl group to give protonated 1,2-diphenylethanes was found to be a minor process (290).

Interesting intermolecular benzylation reactions involving gaseous benzylbenzenium-type ions have been observed upon $\mathrm{CI}\left(i-\mathrm{C}_{4} \mathrm{H}_{10}\right)$ of benzyl acetate (Scheme 28). Field (292-294) reported on the formation of $\mathrm{C}_{14} \mathrm{H}_{13}{ }^{+}$ions at increased pressures and temperatures, and the structure of ortho-benzylbenzyl ions (102) was assigned to these "dimeric" species. This ortho attack is an early parallel to the prevailing ortho alkylation of heterosubstituted benzenes observed upon radiolysis (78), discussed in the previous sections.

Later, Meot-Ner et al. (295) extended the studies on the benzyl acetate system by using time-resolved $\mathrm{CI}$ mass spectrometry and observed the additional formation of the oligobenzyl cations $\mathrm{C}_{7 n} \mathrm{H}_{6 n+1}{ }^{+}(n=3-5)$. Intramolecular cyclization of the ions leads to protonated dihydroanthracenes (103), which expel $\mathrm{H}_{2}$ to give the corresponding anthracenium ions 104, closely similar to the $\mathrm{H}_{2}$ loss discussed for the parent toluenium ions (Section III.B). Cameron and Cooks (296) confirmed this mechanistic picture by MIKE spectrometry of the benzenium type intermediates. Among the rich ion chemistry developed in this study, various 'protonolysis' steps of benzylbenzenium-type ions can be clearly recognized.

It is evident from the investigation discussed above that the gas-phase chemistry of protonated benzyl esters under high-pressure conditions combines, via inter- and intramolecular electrophilic substitution paths, an impressive variety of $\mathrm{C}-\mathrm{C}$ formation reactions of benzyl-type ions with that of arenium-type ions.

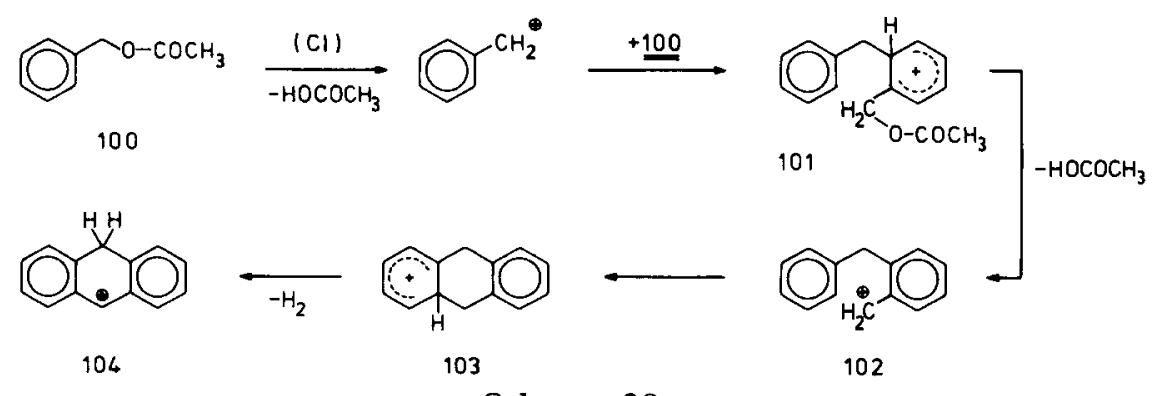

Scheme 28 
<smiles>c1ccc(CC(Cc2ccccc2)Cc2cc[14cH]cc2)cc1</smiles><smiles></smiles>

108
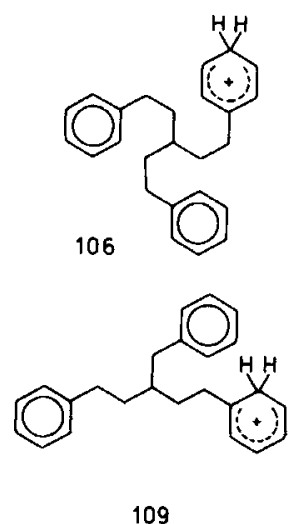

109
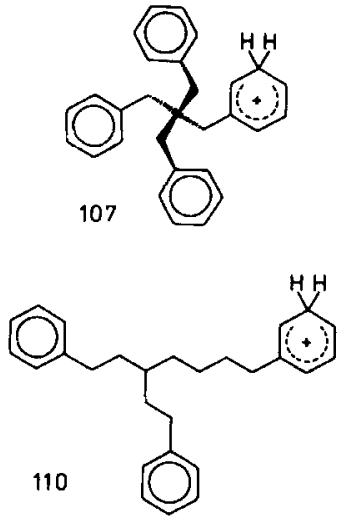

Scheme 29

Intramolecular cyclization is the key step of these reactions. Another example will be presented in the following section. It may be mentioned that, starting from mass spectrometry, the author of this review recently developed a variety of liquid-phase analogies (297-301; see also 295).

\section{Protonated tri- and tetraphenylalkanes}

The fast interannular proton transfer in ( $\omega$-phenylalkyl)-benzenium ions suggests that the protonated and the neutral benzene rings form an intramolecular association complex. Indeed, Meot-Ner et al. $(302,303)$ determined the association enthalpy of the complex $\left[\mathrm{C}_{6} \mathrm{H}_{7}+\cdot \mathrm{C}_{6} \mathrm{H}_{6}\right]$ to be $\Delta H=11 \pm 1.5 \mathrm{kcal} \cdot \mathrm{mol}^{-1}$. Therefore, it was of interest to see whether additional benzene rings would participate in the proton exchange prior to benzene loss. Kuck (272) investigated the interannular proton exchange in protonated tribenzylmethane (105), tris-( $\beta$-phenylethyl)-methane (106), and tetrabenzylmethane (107). Later, these studies were extended to homologs with less symmetrical branching of the aliphatic links (108 and 109) $(273,304)$ and to ring-substituted derivatives (275). Although no hint for longlived intramolecular association complexes were obtained, these large alkylbenzenium ions turned out to be particularly interesting species.

\section{Interannular proton exchange}

In fact, it was found that all of the 16 or, respectively, 21 protons at the aromatic rings of ions 105-109 are fully equilibrated within the ions' lifetime. (Ion 110 has not been studied in this respect.) Again, the hydrogen atoms at the aliphatic core are not involved in this process. Thus, the proton exchange occurs in a sequence of intramolecular association complexes which redissociate fast enough to allow for complete equilibration of the ring protons (Scheme 30). By comparison with the results obtained for the protonated $\alpha, \omega$-diphenylalkanes (7), the rate of interannular proton transfer in protonated tetrabenzylmethane 107 can be estimated to be $k_{H} \gg 10^{7} \mathrm{~s}^{-1}$. 


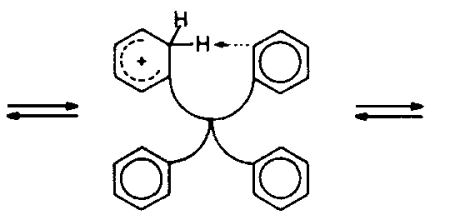

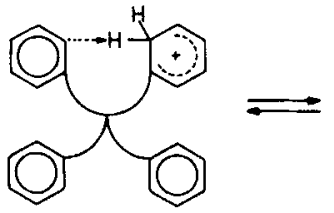

Scheme 30

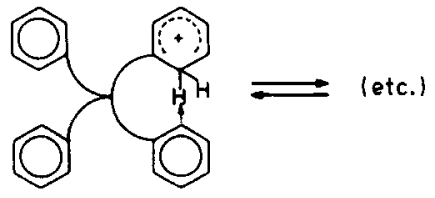

(and tautomers)

As will be shown below, protonated 2-benzylindan 111 and 2,2-dibenzylindan 113 have been suggested as primary fragment ions formed during the loss of benzene from ions 105 and 107. Ions 111 and 113, on their own, undergo complete proton equilibration at the benzene rings. It may be noted that no steric hindrance is observed with these systems, in contrast to ionized 2-benzylindans (e.g., 18, see also Part I), where the hydrogen atoms at the benzo ring do not participate in the intramolecular hydrogen exchange.

The interannular proton exchange in flexible, open-chain protonated $\alpha, \omega$-diphenylalkanes appears to be as ubiquitous as the intraannular one. It seems tempting to design and analyze even larger alkylbenzenium systems to probe for the limiting number of protons that could be randomized within the lifetime of the ions.

\section{The double benzene loss from protonated oligophenylalkanes}

Another peculiar feature of protonated tri- and tetraphenylalkanes is the fast consecutive loss of two molecules of benzene $(272,273,304)$. This process occurs even in metastable ions and is most pronounced in the homologs with symmetrically branched aliphatic skeleton (105-107). The double loss of benzene governs the fragmentation of, notably, metastable ions $105\left(\mathrm{r} \equiv\left[\mathrm{M}+\mathrm{H}-2 \mathrm{C}_{6} \mathrm{H}_{6}\right] /[\mathrm{M}+\mathrm{H}\right.$ $\left.-\mathrm{C}_{6} \mathrm{H}_{6}\right]^{+}=4.4$ ) and $107[\mathrm{r}>60(!)]$, whereas single loss is predominant for the other homologs (106 and 108-110). It has been suggested that the origin of this unusual fragmentation behavior may be related to the fast proton exchange observed in these ions. It seems reasonable to assume that the first benzene molecule

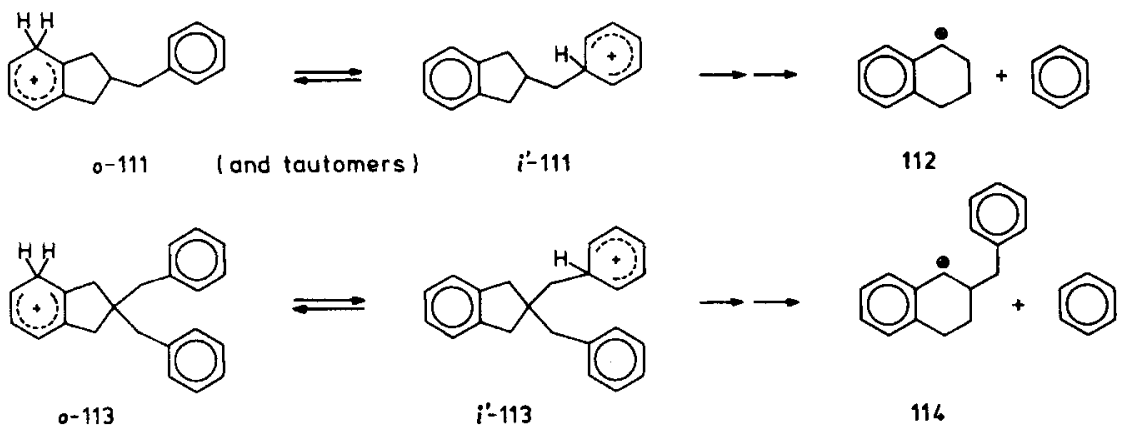

Scheme 31 


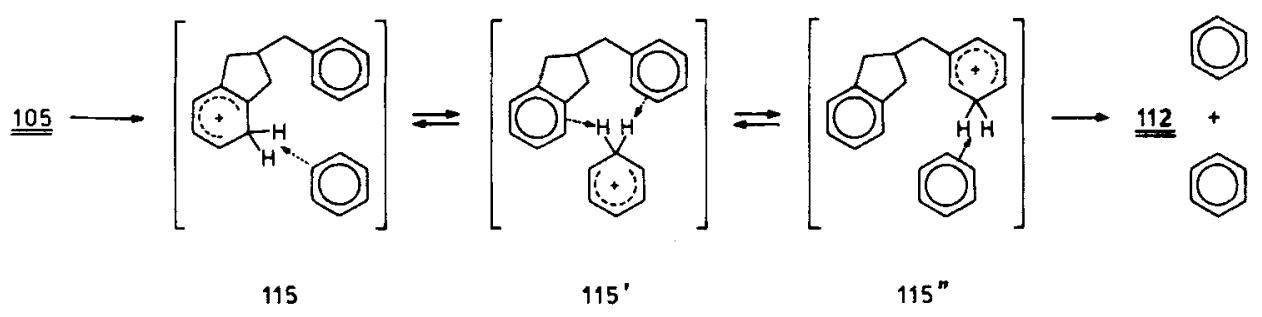

Scheme 32

is formed by remote aryl participation to give ion-molecule complexes containing, again, alkylbenzenium-type ions (e.g.; $\left[111 \cdot \mathrm{C}_{6} \mathrm{H}_{6}\right] \equiv 115$, Scheme 32). These species may be stabilized by the extra entropy of mobile protons shuttled between the large number of nearly equivalent acceptor sites, in accordance with the model advanced by Mason et al. [(29); Section III.B.2].

The ionic components of complexes 115-115" and the related ones formed from ion 107 may eliminate another molecule of benzene, as found to be the case with free ions 111 and 113. Extensive MIKE and CID studies have shown $(273,304)$ that the eventually formed ions $\left[\mathrm{M}+\mathrm{H}-2 \mathrm{C}_{6} \mathrm{H}_{6}\right]^{+}$ions are simple secondary and tertiary carbenium ions (protonated benzocycloalkenes such as 112 and 114, respectively) bearing tightly fixed protons (Scheme 31). Protonated 2,2'-spirobiindan, if formed at all, is not a final product of the double benzene loss.

Thus, it appears that the predominant double benzene loss in ions 105 and 107 originates from the unusually high stability of arenium-arene complexes such as 115, possibly provided by the entropy of fast-moving protons. After formation of the second benzene fragment, the proton mobility is lost, and the two neutrals are released in concert.

\section{E. Comparison to intermolecular proton transfer between arenium ions and arenes}

The truly intermolecular proton exchange between alkylbenzenium ions and alkylbenzenes has been investigated as well. This process is the aromatic variant to the proton or hydrogen atom shuttling in simpler systems as protonated or ionized species like water, ammonia, and methane (305-308) (Scheme 33).

Ausloos and Lias (248) measured the rates of the degenerate proton transfer between a number of simple arenium ions and arenes. The proton exchange is most efficient in the parent system $\left(\mathrm{C}_{6} \mathrm{H}_{7}{ }^{+}+\mathrm{C}_{6} \mathrm{H}_{6}\right)$; in particular, the exchange rate for toluene $\left(\mathrm{C}_{7} \mathrm{H}_{9}{ }^{+}+\mathrm{C}_{7} \mathrm{H}_{8}\right)$ is only half that for benzene. For the fluoroben-

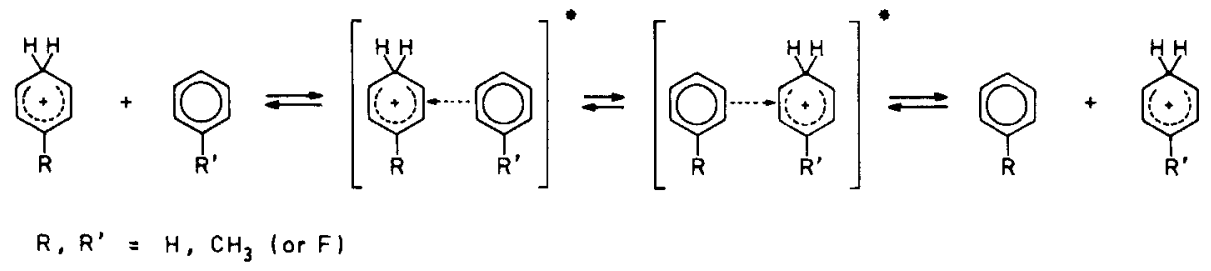


zenes, the rates are smallest. ICR measurements by Kuck et al. (309) qualitatively confirmed the relative exchange rates for the benzene and toluene systems. In addition, it was demonstrated that the proton exchange under ICR conditions occurs within the $\left[\mathrm{C}_{6} \mathrm{H}_{7}{ }^{+} \cdot \mathrm{C}_{6} \mathrm{H}_{6}\right]$ complex as well as by consecutive intermolecular proton transfer. The corresponding mixed complexes formed from $\mathrm{C}_{7} \mathrm{H}_{9}{ }^{+}$ions and $\mathrm{C}_{6} \mathrm{H}_{6}$ (in nonproductive collisions) or, vice versa, during the exothermic proton transfer from $\mathrm{C}_{6} \mathrm{H}_{7}{ }^{+}$to $\mathrm{C}_{7} \mathrm{H}_{8}$, did not undergo proton exchange at all.

Compared with the intermolecular proton exchange processes discussed here, the intramolecular proton transfer in protonated $\alpha, \omega$-diphenylalkanes appears to be remarkably fast. Given the thermodynamic stability of the intermolecular complexes as on the order of $10 \mathrm{kcal} \cdot \mathrm{mol}^{-1}(302)$, this finding implies that the barrier toward proton transfer is relatively high (309), much in contrast to the overall findings obtained with long-chain protonated di- and oligophenylalkanes.

The proton transfer and proton exchange between benzenium ions and alkylbenzenes have been considered in a number of other contexts. The degenerate proton transfer between toluenium ions and toluene has been considered also by Cacace in early nuclear decay experiments (147). Sen Sharma et al. (209), in HPCI studies, observed a slow proton transfer from toluenium ions to tert-butylbenzene. The secondary isotope effect on the protonation of methylbenzenes has been determined (310), but seems to be negligibly small (311).

Yamamoto et al. (312-314) found extensive proton exchange between arenium ions and arenes upon radiolysis of benzene and toluene in a methane or propane atmosphere. As a remarkable parallel to the mechanism suggested for the peculiar double benzene loss from protonated oligophenylalkanes 105 and 107, the formation of ternary complexes (i.e., $\left\langle[\text { alkylbenzene }+\mathrm{H}]^{+} \cdot 2 \mathrm{C}_{6} \mathrm{H}_{6}\right\rangle$ was considered (312). As a general feature, the alkylbenzenes formed showed a much higher degree of exchange than the reactant benzenes. A clear increase with increasing exothermicity of the proton transfer and a negative temperature dependence was found $(313,314)$. In light of the results discussed throughout this review, it seems likely, however, that benzenium and toluenium ions, respectively, are the actual reactants to exchange protons with the alkylbenzenes formed during the radiolysis.

\section{CLOSING REMARKS}

Significant progress has been made in the gas-phase ion chemistry of alkylbenzenes. It started off from the radical cations of benzene and toluene and their protonated analogs, showing some parallels but also considerable differences between ionized and protonated alkylbenzenes. It spanned out to quite large alkylbenzenes with two, three, and four benzene rings, and a case was discovered with 21 mobile protons equilibrating intramolecularly within some microseconds. To understand the fragmentation of many alkylbenzene ions, the site-specific proton affinities of benzenes rings have been found to be of particular value, including ipso protonation (315). The role of intra- and interannular proton migrations as well as skeletal isomerization, including to the classical $\mathrm{C}_{7} \mathrm{H}_{7}{ }^{+}$and 
$\mathrm{C}_{7} \mathrm{H}_{8}{ }^{+}$, but also the $\mathrm{C}_{7} \mathrm{H}_{9}{ }^{+}$ionic systems, has been demonstrated-a harvest from work of many colleagues in a period of merely 35 years.

Hopefully, a number of bridges to both normal organic chemistry in the liquid phase and to physical organic chemistry have been recognized. Yet the author is certain that still many unexpected phenomena will be discovered in the field of ionized and protonated alkylbenzenes. Without doubt, mass spectrometry, this amazingly powerful and increasingly variable technique to uncover organic elementary reactions and to determine their parameters, will help to continue this way.

\section{ACKNOWLEDGMENTS}

The author thanks Professor H. Budzikiewicz and the Arbeitsgemeinschaft Massenspektrometrie (AGMS) for encouraging recognition of his work. He is particularly grateful to Professor H.-F. Grützmacher for support and many discussions, as well as to Dr. W. Bäther and other students and co-workers who worked on mass spectrometry of protonated alkylbenzenes in this laboratory. Valuable discussions with other colleagues are much valued, in particular the hospitality and cooperation of Professor Nico M.M. Nibbering (Amsterdam) and Professor W.J. Richter (Basel) and their colleagues. The author is also thankful to Professor R.G. Cooks, Dr. R. Mason, Professor M.L. Gross, and Professor H.E. Audier for kindly having provided preprints.

\section{REFERENCES}

1. Kuck, D. Mass Spectrom. Rev. 1990, 9, 187-233.

2. Munson, M.S.B.; Field, F.H. J. Am. Chem. Soc. 1966, 88, 2621-2630.

3. Field, F.H. Acc. Chem. Res. 1968, 1, 42-49.

4. Harrison, A.G. "Chemical Ionization Mass Spectrometry"; CRC Press: Boca Raton, FL 1983.

5. Richter, W.J.; Schwarz, H. Angew. Chem. 1978, 90, 449-467; Angew. Chem., Int. Ed. Engl. $1978,17,424$.

6. Harrison, A.G. Adv. Mass Spectrom. 1989, 11A, 582-595.

7. Munson, M.S.B.; Field, F.H. J. Am. Chem. Soc. 1967, 89, 1047-1052.

8. March, J. "Advanced Organic Chemistry, Reactions, Mechanisms, and Structure," 3rd. Ed., John Wiley \& Sons: New York, 1985, Chap. 11.

9. Taylor, R. "Electrophilic Aromatic Substitution"; John Wiley \& Sons: Chichester, 1990.

10. Olah, G.A.; Surya Prakash, G.K,; Sommer, J. "Superacids"; John Wiley \& Sons: New York, 1985.

11. Olah, G.A. Angew. Chem. 1973, 85, 183-234; Angew. Chem., Int. Ed. Engl. 1973, 12, 173.

12. Brouwer, D.M.; Mackor, E.L.; MacLean, C. In: "Carbonium Ions," Vol. 2; Olah, G.A.; Schleyer, P.v.R., Eds., Wiley: New York, 1970, Chap. 20.

13. Ahlberg, P.; Jonsäll, G.; Engdahl, C. Adv. Phys. Org. Chem. 1983, 19, 223-379.

14. Koptyug, V.A. Top. Curr. Chem. 1984, 122, 1-245.

15. Shubin, V.G. Top. Curr. Chem. 1984, 116/117, 267-341.

16. Perkampus, H.-H. Adv. Phys. Org. Chem. 1966, 4, 195-304.

17. Perkampus, H.-H.; Baumgarten, E. Angew. Chem. 1964, 76, 965-972.

18. Radom, L.; Poppinger, D; Haddon, R.C. In: "Carbonium Ions," Vol. 5; Olah, G.A.; Schleyer, P.v.R., Eds., Wiley Interscience: New York, 1976, Chap. 38. 
19. Ghaderi, S.; Kulkarni, P.S.; Ledford, E.B., Jr.; Wilkins, C.L.; Gross, M.L. Anal. Chem. 1981, 53, 428-437.

20. Wilkins, C.L.; Chowdhury, A.K.; Nurwaysir, L.M.; Coates, M.L. Mass Spectrom. Rev. $1989,8,67-92$.

21. Wanzcek, K.P. Int. J. Mass Spectrom. Ion Proc. 1989, 95, 1-38.

22. Kebarle, P. In: "Interactions Between Ions and Molecules"; Ausloos, P., Ed., Plenum Press: New York, 1975, pp. 459-487.

23. Yost, R.A.; Enke, C.G. Anal. Chem. 1979, 51, 1251A-1264A.

24. Cacace, F. Adv. Phys. Org. Chem. 1970, 8, 79-149.

25. Cacace, F. In: "Interactions Between Ions and Molecules"; Ausloos, P., Ed., Plenum Press: New York, 1975, pp. 527-540.

26. Cacace, F. In: "Structure/Reactivity and Thermochemistry of Ions"; Ausloos, P.; Lias, S.G., Eds., D. Reidel Publishing Company: Dordrecht, 1987.

27. Aue, D.H.; Bowers, M.T. In: "Gas Phase Ion Chemistry," Vol. 2; Bowers M.T., Ed., Academic Press: New York, 1979, Chap. 9.

28. Walder, R.; Franklin, J.L. Int. J. Mass Spectrom. Ion Phys. 1980, 36, 85-112.

29. Mason, R.; Fernandez, M.T.; Jennings, K.R. I. Chem. Soc., Faraday Trans. 2 1987, 83, 89109.

30. Lias, S.G.; Bartmess, J.E.; Holmes, J.L.; Levin, R.D.; Liebman, J.F.; Mallard, W.G. J. Phys. Chem. Ref. Data 1988, 17, Suppl. No. 1.

31. Vogel, P. "Carbocation Chemistry"; Elsevier: Amsterdam, 1985.

32. Grubb, H.M.; Meyerson, S. In: "Mass Spectrometry of Organic Ions"; McLafferty, F.W., Ed., Academic Press: New York, 1963, Chap. 10.

33. Budzikiewicz, H.; Djerassi, C.; Williams, D.H. "Mass Spectrometry of Organic Compounds"; Holden-Day: San Francisco, 1967, Chap. 1.

34. Kuck, D.; Bäther, W.; Grützmacher, H.-F. J. Am. Chem. Soc. 1979, 101, 7154-7157.

35. Kuck, D.; Schneider, J.; Grützmacher, H.-F. J. Chem. Soc., Perkin Trans. 2 1985, 689-696.

36. Kuck, D.; Bäther, W.; Grützmacher, H.-F. Int. J. Mass Spectrom. Ion Proc. 1985, 67, 7591.

37. Bäther, W.; Kuck, D.; Grützmacher, H.-F. Org. Mass Spectrom. 1985, 20, 589-591.

38. Bäther, W.; Kuck; D.; Grützmacher, H.-F. Org. Mass Spectrom. 1985, 20, 572-577.

39. Bäther, W. Doctoral thesis, Universität Bielefeld, 1984.

40. Bäther, W.; Grützmacher, H.-F. Int. J. Mass Spectrom. Ion Proc. 1985, 64, 193-212.

41. Kuck, D.; Prior, G.; Grützmacher, H.-F. Extended Abstracts of the 14th Meeting of the British Mass Spectrometry Society, Edinburgh 1984, Paper 42.

42. Kuck, D.; Prior, G.; Grützmacher, H.-F.; Müller, D.R.; Richter, W.J. Adv. Mass Spectrom. 1989, 11A, 750-751.

43. Olah, G.A.; Kuhn, S.J. J. Am. Chem. Soc. 1958, 80, 6540-6541.

44. Beynon, J.H.; Saunders, R.A.; Williams, A.E. "The Mass Spectra of Organic Molecules"; Elsevier: Amsterdam, 1968, Chap. 3.

45. Robert-Lopes, M.T.; Nunes Duarte, M.F.T.; Neves Fernandez, M.T. 12th Meeting of the British Mass Spectrometry Society, Cambridge 1981, Paper SI 10.

46. Schwarz, H.; Borchers, F.; Levsen, K. Z. Naturforsch. B 1976, 31, 935-940.

47. Grützmacher, H.-F.; Heer-Neugebauer, U. In: "Entwicklung und Fortschritte der Forensischen Chemie"; Arnold, W.; Püschel, K., Ed., Verlag Dr. D. Helm: Hamburg, 1982.

48. Levsen, K.; Hilt, E. Liebigs Ann. Chem. 1976, 257-268.

49. Franklin, J.L.; Carroll, S.R. J. Am. Chem. Soc. 1969, 91, 6564-6569.

50. Allan, M.; Dannacher, J.; Maier, J.P. J. Chem. Phys. 1980, 73, 3114-3122.

51. Lias, S.G.; Ausloos, P. J. Chem. Phys. 1985, 82, 3613-3624.

52. Shannon, J.S. Aust. J. Chem. 1962, 15, 265-277.

53. Cooks, R.G.; Beynon, J.H.; Bertrand, M., Hoffman, M.K. Org. Mass Spectrom. 1973, 7, 1303-1312.

54. Williams, D.H.; Hvistendahl, G. J. Am. Chem. Soc. 1974, 96, 6755-6757.

55. Uccella, N. Org. Mass Spectrom. 1975, 10, 494-502.

56. Harrison, A.G. In: "Topics in Organic Mass Spectrometry," Vol. 8; Burlingame, A.L., Ed., Wiley-Interscience: New York, 1970. 
57. Harrison, A.G.; Haynes, P.; McLean, S.; Meyer, F. J. Am. Chem. Soc, 1965, 87, 50995105.

58. Winters, R.E.; Collins, J.H. Org. Mass Spectrom. 1969, 2, 299-308.

59. Hammerum, S. Mass Spectrom. Rev. 1988, 7, 123-202.

60. Kuck, D.; Grützmacher, H.-F. Org. Mass Spectrom. 1978, 13, 90-102.

61. Kuck, D.; Grützmacher, H.-F. Adv. Mass Spectrom. 1980, 8, 867-878.

62. Kuck, D. Org. Mass Spectrom. 1989, 24, 1077-1080.

63. Kingston, E.E.; Eichholzer, J.V.; Lyndon, P.; MacLeod, J.K.; Summons, R.E. Org. Mass Spectrom. 1988, 23, 42-47.

64. Melton, C.E. In: "Mass Spectrometry of Organic Ions", McLafferty, F.W., Ed., Academic Press: New York, 1963, Chap. 2.

65. Ervin, K.M.; Armentrout, P.B. J. Chem. Phys. 1985, 83, 166-189.

66. Lifshitz, C.; Gleitman, Y.; Gefen, S.; Shainok, U.; Dotan, I. Int. J. Mass Spectrom. Ion Phys. 1981, 40, 1-16.

67. Lifshitz, C.; Gleitman, Y. Int. J. Mass Spectrom. Ion Phys. 1981, 40, 17-29.

68. Lifshitz, C.; Gleitman, Y. J. Chem. Phys. 1982, 77, 2383-2386.

69. Knight, J.S.; Freeman, C.G.; McEwan, M.J.; Anicich, V.G.; Huntress, W.T., Jr. J. Phys. Chem. 1987, 91, 3898-3902.

70. Gross, M.L.; Russell, D.H.; Aerni, R.J.; Bronczyk, S.A. J. Am. Chem. Soc. 1977, 99, 36033609.

71. Miller, D.L.; Gross, M.L. J. Am. Chem. Soc. 1983, 105, 3783-3788.

72. Holman, R.W.; Gross, M.L. Int. J. Mass Spectrom. Ion. Proc. 1989, 92, 79-92.

73. Audier, H.E.; Monteiro, C.; Robin, D. New J. Chem. 1989, 13, 621-624.

74. Lau, Y.K.; Kebarle, P. J. Am. Chem. Soc. 1976, 98, 7452-7453.

75. Yamdagni, R.; Kebarle, P. J. Am. Chem. Soc. 1976, 98, 1320-1324.

76. Haney, M.A.; Franklin, J.L. J. Phys. Chem. 1969, 73, 4328-4331.

77. Chong, S.-L.; Franklin, J.L. J. Am. Chem. Soc. 1972, 94, 6630-6635.

78. Cacace, F. Acc. Chem. Res. 1988, 21, 215-222.

79. Bartmess, J.E. J. Am. Chem. Soc. 1982, 104, 335-337.

80. Attinà, M.; Cacace, F.; de Petris, G.; Fornarini, S.; Giacomello, P. J. Am. Chem. Soc. 1985, 107, 2297-2302.

81. Sen Sharma, D.K.; Kebarle, P. J. Am. Chem. Soc. 1982, 104, 19-24.

82. Lay, J.O., Jr.; Gross, M.L. J. Am. Chem. Soc. 1983, 105, 3445-3451.

83. Kieu My, N.; Schilling, M.; Schwarz, H. Org. Mass Spectrom. 1987, 22, 254-258.

84. Kuck, D.; Bäther, W. Org. Mass Spectrom. 1986, 21, 451-457.

85. Speranza, M.; Sefcik, M.D.; Henis, J.M.S.; Gaspar, P.P. J. Am. Chem. Soc. 1977, 99, 55835589.

86. Angelini, G.; Sparapani, C.; Speranza, M. Tetrahedron 1984, 40, 4865-4871.

87. Colosimo, M.; Speranza, M.; Cacace, F.; Ciranni, G. Tetrahedron 1984, 23, 4873-4883.

88. Harrison, A.G.; Lin, P.-H. Can. J. Chem. 1975, 53, 1314-1318.

89. Leung, H.-W.; Harrison, A.G. Can. J. Chem. 1976, 54, 3439-3452.

90. Leung, H.-W.; Ichikawa, H.; Li, Y.-H.; Harrison, A.G. J. Am. Chem. Soc. 1978, 100, 2479 2484 .

91. Leung, H.-W.; Harrison, A.G. J. Am. Chem. Soc. 1980, 102, 1623-1628.

92. Cacace, F.; Speranza, M. J. Am. Chem. Soc. 1976, 98, 7299-7304.

93. Cacace, F.; Speranza, M. J. Am. Chem. Soc. 1976, 98, 7305-7307.

94. Blom, K.F.; Munson, B. Anal. Chem. 1986, 58, 2001-2009.

95. Kuck, D.; Prior, G.; Grützmacher, H.-F.; Müller, D.R.; Richter, W.J., to be published.

96. Brown, H.C.; Brady, J.D. J. Am. Chem. Soc. 1952, 74, 3570-3582.

97. Pfeiffer, P.; Wizinger, R. Liebigs Ann. Chem. 1928, 461, 132-154.

98. Wheland, G.W. J. Am. Chem. Soc. 1942, 64, 900-908.

99. Olah, G.A. J. Am. Chem. Soc. 1972, 94, 808-820.

100. Olah, G.A.; Schlosberg, R.H.; Kelly, D.P.; Mateescu, G.D. I. Am. Chem. Soc. 1970, 92, 2546-2548.

101. Olah, G.A.; Schlosberg, R.H.; Porter R.D.; Mo, Y.K.; Kelly, D.P.; Mateescu, G.D. J. Am. Chem. Soc. 1972, 94, 2034-2043.

102. Schuster, P.; Jakubetz, W. Angew. Chem., Int. Ed. Engl. 1971, 10, 497-498. 
103. Jakubetz, W.; Schuster, P. Tetrahedron 1971, 27, 101-112.

104. Hehre, W.J.; Pople, J.A. J. Am. Chem. Soc. 1972, 94, 6901-6904.

105. Ermler, W.C.; Mulliken, R.S.; Clementi, E. J. Am. Chem. Soc. 1976, 98, 388-394.

106. Köhler, H.-J.; Lischka, H. J. Am. Chem. Soc. 1979, 101, 3479-3486.

107. Hehre, W.J. In: "Modern Theoretical Chemistry," Vol. 4; Schaefer, H.F., III, Ed., Plenum Press: New York, 1977, Chap. 7.

108. Schoeller, W.W.; Schenck, G.E. Tetrahedron 1973, 29, 425-427.

109. Gleghorn, J.T.; McConkey, F.W. J. Chem. Soc., Perkin Trans. 2 1976, 1078-1082.

110. Heidrich, D.; Grimmer, M. Intern. J. Quantum Chem. 1975, 9, 923-940.

111. Heidrich, D.; Hobza, P.; Cársky, P.; Zahradník, R. Coll. Czech. Chem. Commun. 1978, 43, 3020-3023.

112. Sordo, T.; Bertrán J.; Canadell, E. J. Chem. Soc., Perkin Trans. 2 1979, 1486-1489.

113. Helgstrand, E. Acta Chem. Scand. 1970, 24, 3687-3696.

114. Mason, R.; Fernandez, M.T.; Jennings, K.R. J. Chem. Soc., Faraday Trans. 2 1987, 83, 89109.

115. Dewar, M.J.S.; Dieter, K.M. J. Am. Chem. Soc. 1986, 108, 8075-8086.

116. Olah, G.A.; Staral, J.S.; Asencio, G.; Liang, G.; Forsyth, D.A.; Mateescu, G.D. J. Am. Chem. Soc. 1978, 100, 6299-6308.

117. Holmes. J.L.; Lossing, F.P. Int. J. Mass Spectrom. Ion Proc. 1989, 92, 111-122.

118. Franchetti, V.; Freiser, B.S.; Cooks, R.G. Org. Mass Spectrom. 1978, 13, 106-110.

119. Hvistendahl, G.; Williams, D.H. J. Chem. Soc., Perkin Trans 2 1975, 4-6.

120. Hvistendahl, G.; Williams, D.H. J. Chem. Soc., Perkin Trans 2 1975, 881-885.

121. Freiser, B.S.; Beauchamp, J.L. J. Am. Chem. Soc. 1976, 98, 3136-3139.

122. Freiser, B.S.; Beauchamp, J.L. J. Am. Chem. Soc. 1977, 99, 3214-3225.

123. McMahon, A.W.; Chadikun, F.; Harrison, A.G.; March, R.E. Int. J. Mass Spectrom. Ion Proc. 1989, 87, 275-285.

124. Field, F.H. J. Am. Chem. Soc. 1967, 89, 5328-5334.

125. Grubb, H.M.; Meyerson, S. In: "Mass Spectrometry of Organic Ions"; McLafferty, F.W., Ed., Academic Press: New York, 1963, Chap. 10.

126. Meyer, F.; Harrison, A.G. J. Am. Chem. Soc. 1964, 86, 4757-4761.

127. Klotz, H.-D.; Drost, H.; Schulz, W. Z. Naturforsch. A 1968, 23, 1690-1691.

128. Klotz, H.-D.; Drost, H.; Weixelbaum, L. Z. Phys. Chem., Leipzig 1973, 253, 1-11.

129. Klotz, H.-D.; Drost, H. Org. Mass Spectrom. 1972, 6, 647-653.

130. Devlin, J.L.; Wolf, J.F.; Taft, R.W.; Hehre, W.J. J. Am. Chem. Soc. 1976, 98, 1990-1992.

131. Heidrich, D.; Grimmer, M.; Sommer, B. Tetrahedron 1976, 32, 2027-2032.

132. Hehre, W.J.; McIver, R.T.; Pople, J.A.; Schleyer, P.v.R. J. Am. Chem. Soc. 1974, 96, 71627163.

133. Catalán, J.; Yánez, M. J. Chem. Soc., Perkin Trans. 2 1979, 1627-1631.

134. Catalán, J.; Yánez, M. J. Chem. Soc., Perkin Trans. 2 1979, 741-746.

135. Fărcaşiu, D.; Melchior, M.T.; Craine, L. Angew, Chem., Int. Ed. Engl. 1977, 16, 315-316.

136. Fărcaşiu, D. Acc. Chem. Res. 1982, 15, 46-51.

137. Martinsen, D.P.; Buttrill, S.E., Jr. Org. Mass Spectrom. 1976, 11, 762-772.

138. Hunt, D.F.; Sethi, S.K. J. Am. Chem. Soc. 1980, 102, 6953-6963.

139. Freiser, B.S.; Woodin, R.L.; Beauchamp, J.L. J. Am. Chem. Soc. 1975, 97, 6893-6894.

140. Grimmer, M.; Heidrich, D. Z. Chem. 1974, 14, 481-482.

141. Heidrich, D.; Göring, U.; Förster, W.; Weiss, C. Tetrahedron 1979, 35, 651-655.

142. Olah, G.A.; Mo., Y.K. J. Am. Chem. Soc. 1972, 94, 9241-9244.

143. Olah, G.A.; Mo., Y.K. J. Org. Chem. 1973, 38, 3212-3223.

144. Fernandez, M.T.; Jennings, K.R.; Mason, R. J. Chem. Soc., Faraday Trans 2 1987, 83, 159171.

145. Fernandez, M.T.; Jennings, K.R.; Mason, R.S. Adv. Mass Spectrom. 1986, 10, 1163-1164.

146. Fernandez, M.T.; Jennings, K.R.; Mason, R.S. Adv. Mass Spectrom. 1986, 10, 1167-1168.

147. Cacace, F.; Cipollini, R.; Occhiucci, G. J. Chem. Soc., Perkin Trans. 2 1972, 84-88.

148. Cacace, F.; Caronna, S. J. Am. Chem. Soc. 1967, 89, 6848-6854.

149. Steinberg, H.; Sixma, F.L.J. Recl. Trav. Chim. Pays-Bas 1962, 81, 185-197.

150. Koptyug, V.A.; Shubin, V.G.; Rezbukhin, A.I.; Korchangina, D.V.; Tret'yakov, V.P.; Rudakov, E.S. Dokl. Chem., Akad. Nauk SSSR 1966, 171, 1109-1112. 
151. Brouwer, D.M. Recl. Trav. Chim. Pays-Bas 1968, 87, 611-622.

152. Cacace, F.: Giacomello, P. J. Chem. Soc., Perkin Trans 2 1978, 652-658.

153. Cacace, F.; Giacomello, P. J. Am. Chem. Soc. 1977, 99, 5477-5478.

154. McIver, R.T., Jr. Org. Mass Spectrom. 1975, 10, 396-399.

155. Dunbar, R.C.; Fu, E.W.; Olah, G.A. J. Am. Chem. Soc. 1977, 99, 7502-7503.

156. Wolfschütz, R.; Schwarz, H. Int. J. Mass Spectrom. Ion. Phys. 1980, 33, 291-297.

157. Doering, W. von E.; Saunders, M.; Boyton, H.G.; Earhart, H.W.; Wadley, E.F.; Edwards, W.R.; Laber, G. Tetrahedron 1958, 4, 178-185.

158. Woodward, R.B.; Hoffmann, R. Angew. Chem., Int. Ed. Engl. 1969, 8, 781-853.

159. Trong Anh, N. "Die Woodward-Hoffmann-Regeln und ihre Anwendung"; Verlag Chemie: Weinheim, 1972.

160. Williams, D.H.; Hvistendahl, G. J. Am. Chem. Soc. 1974, 96, 6753-6755.

161. Aquilanti, V.; Giardini Guidoni, A.; Volpi, G.G. Trans. Faraday Soc. 1968, 64, 3282-3287.

162. Baldwin, M.A.; McLafferty, F.W.; Jerina, D.M. J. Am. Chem. Soc. 1975, 97, 6169-6174.

163. Morrison, J.D.; Stanney, K.; Tedder, J.M. J. Chem. Soc., Perkin Trans. 2 1981, 838-841.

164. Morrison, J.D.; Stanney, K.; Tedder, J.M. J. Chem. Soc., Perkin Trans. 2 1981, 967-969.

165. Beauchamp, J.L. In: "Interactions Between Ions and Molecules"; Ausloos, P., Ed., Plenum Press: New York, 1975, p. 435.

166. Blint, R.J. Ph.D. thesis, California Institute of Technology, 1972.

167. Benezra, S.A.; Hoffman, M.K.; Bursey, M.M. J. Am. Chem. Soc. 1970, 92, 7501-7502.

168. Cacace, F. J. Chem. Soc., Perkin Trans. 2 1982, 1129-1132.

169. Miller, D.L.; Lay, J.O.; Gross, M.L. Chem. Commun. 1982, 970-972.

170. Schleyer, P.v.R. Adv. Mass Spectrom. 1985, 10, 287-301.

171. Olah, G.A.; Surya Prakash, G.K., Williams, R.E.; Field, L.D.; Wade, K. "Hypercarbon Chemistry"; John Wiley \& Sons: New York, 1987.

172. Hiraoka, K.; Kebarle, P. J. Am. Chem. Soc. 1976, 98, 6119-6125.

173. Houriet, R.; Parisod, G.; Gäumann, T. J. Am. Chem. Soc. 1977, 99, 3599-3602.

174. Roberts, R.M.; Gibson, T.L. In: "Isotopes in Organic Chemistry," Vol. 5, Buncel, E., Ed., Elsevier: Amsterdam, 1980, Chap. 3.

175. Lifshitz, C.; Gibson, D.; Levsen, K. Int. J. Mass Spectrom. Ion Phys. 1980, 35, 365-370.

176. Ausloos, P.; Lias, S.G.; Buckley, T.J.; Rogers, E.E. Int. J. Mass Spectrom. Ion Proc. 1989, 92, 65-77.

177. Harrison, A.G.; Lin, P.-H.; Leung, H.-W. Adv. Mass Spectrom. 1978, 7, 1395-1401.

178. Wesdemiotis, C.; Schwarz, H.; Van de Sande, C.C.; Van Gaever, F. Z. Naturforsch. B 1979, 34, 495-501.

179. Herman, J.A.; Harrison, A.G. Org. Mass Spectrom. 1981, 16, 423-427.

180. Leung, H.-W.; Harrison, A.G. Org. Mass Spectrom. 1977, 12, 582-586.

181. Harrison, A.G. Can. J. Chem. 1986, 64, 1051-1053.

182. Arnett, E.M.; Abboud, J.-L.M. J. Am. Chem. Soc. 1975, 97, 3865-3867.

183. Wesdemiotis, C.; Schwarz, H.; Borchers, F.; Heimbach, H.; Levsen, K. Z. Naturforsch. $B$ 1978, 33, 1150-1164.

184. Vogel, P. In ref. 31, Chap. 7, p. 267.

185. Bowen, R.D.; Williams, D.H.; Schwarz, H. Angew. Chem., Int. Ed. Engl. 1979, 18, 451461.

186. Bowen, R.D. J. Chem. Soc., Perkin Trans. 2 1989, 913-918.

187. Prior, G.; Kuck, D.; Grützmacher, H.-F. 19th Diskussionstagung der Arbeitsgemeinschaft Massenspektrometrie, Mainz (FRG), May 1986.

188. Robin, D.; Hudhomme, P.; Audier, H.E. Adv. Mass Spectrom. 1989, 11A, 614-615.

189. McAdoo, D.J. Mass Spectrom. Rev. 1988, 7, 363-393.

190. Chronister, E.L.; Morton, T.H. J. Am. Chem. Soc. 1990, 112, 133-139.

191. Hammerum, S. J. Chem. Soc., Chem. Commun. 1988, 858-859.

192. Vorachek, J.H.; Meisels, G.G.; Geanangle, R.A.; Emmel, R.H, J. Am. Chem. Soc. 1973, $95,4078-4080$.

193. Ausloos, P.; Rebbert, R.E.; Sieck, L.W.; Tiernan, T.O. J. Am. Chem. Soc. 1972, 94, 89398941.

194. Dewar, M.J.S., Rzepa, H.S. J. Am. Chem. Soc. 1977, 99, 7432-7439.

195. Lischka, H.; Köhler, H.-J. J. Am. Chem. Soc. 1978, 100, 5297-5305. 
196. Pople, J.A. Int. J. Mass Spectrom. Ion Phys. 1976, 19, 89-106.

197. Vogel, P. In ref. 31, chap. 8.1.1.

198. Fry, J.L.; Karabatsos, G.J. In: "Carbonium Ions," Vol. 2; Olah, G.A.; Schleyer, P.v.R. Eds., Wiley-Interscience: New York, 1970, Chap. 14.

199. Holman, R.W.; Gross, M.L. J. Am. Chem. Soc. 1989, 111, 3560-3565.

200. Audier, H.E.; Monteiro, C.; Mourgues, P.; Berthomieu, D. Org. Mass Spectrom. 1990, 25, 245-246.

201. Cacace, F.; Possagno, E. J. Am. Chem. Soc. 1973, 95, 3397-3399.

202. Takamuku, S.; Iseda, K.; Sakurai, H. J. Am. Chem. Soc. 1971, 93, 2420-2425.

203. Attinà, M.; Cacace, F.; Ciranni, G.; Giacomello, P. J. Am. Chem. Soc. 1977, 99, 2611-2615.

204. Cacace, F.; Giacomello, P. J. Am. Chem. Soc. 1973, 95, 5851-5856.

205. Giacomello, P.; Cacace, F. J. Am. Chem. Soc. 1976, 98, 1823-1828.

206. Cacace, F.; Ciranni, G.; Giacomello, P. J. Chem. Soc., Perkin Trans. 2 1982, 1373-1377.

207. Cacace, F.; Ciranni, G.; Giacomello, P. J. Am. Chem. Soc. 1981, 103, 1513-1516.

208. Ausloos, P.; Lias, S.G. Int. J. Mass Spectrom. Ion Proc. 1984, 58, 165-180.

209. Sen Sharma, D.K.; Ikuta, S.; Kebarle, P. Can. J. Chem. 1982, 60, 2325-2331.

210. Cacace, F.; Ciranni, G. J. Am. Chem. Soc. 1986, 108, 887-890.

211. Attinà, M.; Giacomello, P. J. Am. Chem. Soc. 1979, 101, 6040-6045.

212. Aliprandi, B.; Cacace, F.; Fornarini, S. Tetrahedron 1987, 43, 2831-2841.

213. Attinà, M.; Cacace, F. J. Am. Chem. Soc. 1983, 105, 1122-1126.

214. Attinà, M.; Cacace, F.; Ciranni, G.; Giacomello, P. J. Am. Chem. Soc. 1977, 99, 4101-4105.

215. Pepe, N.; Speranza, M. J. Chem. Soc., Perkin Trans. 2, 1981, 1430-1436.

216. Cacace, F.; de Petris, G.; Fornarini, S.; Giacomello, P. J. Am. Chem. Soc. 1986, 108, 74957501.

217. Speranza, M.; Cacace, F. J. Am. Chem. Soc. 1977, 99, 3051-3055.

218. Attinà, M.; de Petris, G.; Giacomello, G. Tetrahedron Lett. 1982, 23, 3525-3528.

219. Aliprandi, B., Cacace, F. J. Radioanal. Nucl. Chem. 1985, 92, 357-362.

220. Bone, L.I.; Futrell, J.H. J. Chem. Phys. 1967, 47, 4366-4372.

221. Wojtyniak, A.C.M.; Stone, J.A. Int. J. Mass Spectrom. Ion Proc. 1986, 74, 59-79.

222. Cacace, F.; Crestoni, M.E.; Fornarini, S.; Gabrielli, R. Int. J. Mass Spectrom. Ion Proc. 1988, $84,17-32$.

223. Fornarini, S. J. Org. Chem. 1988, 53, 1314-1316.

224. Cacace, F.; Crestoni, M.E.; de Petris, G.; Fornarini, S.; Grandinetti, F. Can. J. Chem. 1988, 66, 3099-3107.

225. Fornarini, S.; Speranza, M. J. Am. Chem. Soc. 1985, 107, 5358-5363.

226. Harrison, A.G.; Houriet, R.; Tidwell, T.T. J. Org. Chem. 1984, 49, 1302-1304.

227. Catalán J.; Yánez, M. J. Chem. Soc., Perkin Trans. 2 1979, 1627-1631.

228. Kafafi, S.A.; Meot-Ner (Mautner), M.; Liebman, J.F. Struct. Chem. 1989, 1, 101-105.

229. Olah, G.A.; Porter, R.D. J. Am. Chem. Soc. 1971, 93, 6877-6887.

230. Olah, G.A.; Spear, R.J.; Forsyth, D.A. J. Am. Chem. Soc. 1976, 98, 6284-6289.

231. Fornarini, S.; Muraglia, V. J. Am. Chem. Soc. 1989, 111, 873-877.

232. Fornarini, S.; Sparapani, C.; Speranza, M. J. Am. Chem. Soc. 1988, 110, 42-46.

233. Köppel, C.; Van der Sande, C.C.; Nibbering, N.M.M.; Nishishita, T.; McLafferty, F.W. J. Am. Chem. Soc. 1977, 99, 2883-2888.

234. McLafferty, F.W. In: "High Performance Mass Spectrometry: Chemical Applications"; Gross, M.L., Ed., American Chemical Society: Washington, D.C., 1978, Chap. 3.

235. Clow, R.P.; Futrell, J.H. J. Am. Chem. Soc. 1972, 94, 3748-3755.

236. Houriet, R.; Elwood, T.A.; Futrell, J.H. J. Am. Chem. Soc. 1978, 100, 2320-2324.

237. Greenberg, A.; Liebman, J.F. J. Org. Chem. 1982, 47, $2084-2088$.

238. Colosimo, M.; Bucci, R. J. Chem. Soc., Perkin Trans. 2 1982, 461-464.

239. Attinà, M.; Cacace, F.; de Petris, G.; di Marzio, A.; Giacomello, P. Int. J. Mass Spectrom. Ion Proc. 1989, 93, 185-198.

240. Crestoni, M.E.; Fornarini, S. J. Am. Chem. Soc. 1989, 111, 6008-6014.

241. Galli, C; Speranza, M. Org. Mass Spectrom. 1989, 24, 139-143.

242. Melloni, G.; Modena, G.; Tonellato, U. Acc. Chem. Res. 1981, 14, 227-233.

243. Apeloig, Y.; Franke, W.; Rappoport, Z.; Schwarz, H.; Stahl, D. J. Am. Chem. Soc. 1981, 105, 2770-2780. 
244. Marcuzzi, F.; Modena, G; Paradisi, C. J. Org. Chem. 1985, 50, 4973-4975.

245. Ausloos, P.; Lias, S.G. J. Am. Chem. Soc. 1981, 103, 6505-6507.

246. Wolfschütz, R.; Schwarz, H. Int. J. Mass Spectrom. Ion Phys, 1980, 33, 285-290.

247. Harris, J.A.; Morgan, R.P.; Beynon, J.H. Org. Mass Spectrom. 1979, 14, 4-8.

248. Ausloos, P.; Lias, S.G. J. Am. Chem. Soc. 1981, 103, 3641-3647.

249. McKelvey, J.M.; Alexandratos, S.; Streitwieser, A., Jr.; Abboud, J.-L.M.; Hehre, W.J. J. Am. Chem. Soc. 1976, 98, 244-246.

250. De Frees, D.J.; McIver, R.T., Jr.; Hehre, W.J. J. Am. Chem. Soc. 1977, 99, 3853-3854.

251. Pollack, S.K.; Devlin, J.L., III, Summerhays, K.D.; Taft, R.W.; Hehre, W.J. J. Am. Chem. Soc. 1977, 99, 4583-4584.

252. Summerhays, K.D.; Pollack, S.K.; Taft, R.W.; Hehre, W.J. J. Am. Chem. Soc. 1977, 99, $4585-5487$.

253. Lau, Y.K.; Nishizawa, K.; Tse, A.; Brown, R.S.; Kebarle, P. J. Am. Chem. Soc. 1981, 103, 6291-6295.

254. Wood, K.V.; Burinsky, D.J.; Cameron, D.; Cooks, R.G. J. Org. Chem. 1983, 48, 52365242.

255. Hartman, K.G.; Lias, S.G. Int. J. Mass Spectrom. Ion Phys, 1978, 28, 213-223.

256. Olah, G.A.; Kiovsky, G.E. J. Am. Chem. Soc. 1967, 89, 5692-5694.

257. Mason, R.; Milton, D.; Harris, F. Adv. Mass Spectrom. 1989, 11A, 856-857.

258. Mason, R.; Milton, D.; Harris, F. J. Chem. Soc., Chem. Commun. 1987, 1453-1455.

259. Vulpius, T.; Hammerum, S.; Houriet, R. Adv. Mass Spectrom. 1988, 11A, 578-579.

260. Hehre, W.J.; Hiberty, P.C. J. Am. Chem. Soc. 1974, 96, 7163-7165.

261. Dewar, M.J.S.; Reynolds, C.H. J. Am. Chem. Soc. 1982, 104, 3244-3246.

262. Maquestiau, A.; Van Haverbeke, Y.; Mispreuve, H.; Flammang, R.; Harris, J.A.; Howe, I.; Beynon, J.H. Org. Mass Spectrom. 1980, 15, 144-148.

263. Pachuta, S.J.; Isern-Flecha, I.; Cooks, R.G. Org. Mass. Spectrom. 1986, 21, 1-5.

264. Kruger, T.L.; Flammang, R.; Litton, J.F.; Cooks, R.G. Tetrahedron Lett. 1976, 4555-4558.

265. Kuck, D.; Grützmacher, H.-F. Org. Mass Spectrom. 1978, 13, 81-89.

266. Kuck, D.; Grützmacher, H.-F. Org. Mass Spectrom. 1978, 13, 90-102.

267. Kuck, D.; Grützmacher, H.-F. Org. Mass Spectrom 1979, 14, 86-97.

268. Kuck, D.; Grützmacher, H.-F. Adv. Mass Spectrom. 1980, 8, 867-878.

269. Kuck, D.; Grützmacher, H.-F. Z. Naturforsch. B. 1979, 34, 1750-1764.

270. Kuck, D. Adv. Mass Spectrom. 1986, 10, 773-774.

271. Kuck, D.; Filges, U. Org. Mass Spectrom. 1988, 23, 643-653.

272. Kuck, D. Int. J. Mass Spectrom. Ion Phys. 1983, 47, 499-502.

273. Kuck, D.; Fastabend, U. Adv. Mass Spectrom. 1989, 11A, 904-905.

274. Kuck, D.; Thölmann, D.; Grützmacher, H.-F. J. Chem. Soc., Perkin Trans. 2 1990, 251256.

275. Demmer, U. Doctoral thesis, Universität Bielefeld, 1988.

276. Wexler, S.; Clow, R.P. J. Am. Chem. Soc. 1968, 90, 3940-3945.

277. Giardini-Guidoni, A.; Zocchi, F. Trans. Faraday Soc. 1968, 64, 2342-2347.

278. Yamamoto, Y.; Takamuku, S.; Sakurai, H. J. Am. Chem. Soc. 1969, 91, 7192-7194.

279. Yamamoto, Y.; Takamuku, S.; Sakurai, H. J. Phys. Chem. 1970, 74, 3325-3332.

280. Yamamoto, Y.; Takamuku, S.; Sakurai, H. Bull. Chem. Soc. Japan 1971, 44, 2104-2107.

281. Yamamoto, Y.; Takamuku, S.; Sakurai, H. J. Am. Chem. Soc. 1972, 94, 661-663.

282. Shen, J.; Dunbar, R.C.; Olah, G.A. J. Am. Chem. Soc. 1974, 96, 6227-6229.

283. Dunbar, R.C. J. Am. Chem. Soc. 1973, 95, 472-476.

284. Dunbar, R.C. J. Am. Chem. Soc. 1975, 97, 1382-1384.

285. Jackson, J.-A.A.; Lias, S.G.; Ausloos, P. J. Am. Chem. Soc. 1977, 99, 7515-7521.

286. Ausloos, P.; Jackson, J.-A.A., Lias, S.G. Int. J. Mass Spectrom. Ion Phys. 1980, 33, 269283.

287. Ausloos, P. J. Am. Chem. Soc. 1982, 104, 5259-5265.

288. Sen Sharma, D.K.; Kebarle, P. Can. J. Chem. 1981, 59, 1592-1601.

289. Kingston, E.E.; Shannon, J.S.; Diakiw, V.; Lacey, M.J. Org. Mass Spectrom. 1981, 16, 428 440 .

290. Kingston, E.E.; Shannon, J.S.; Lacey, M.J. Org. Mass Spectrom. 1987, 22, 30-35.

291. Kingston, E.E.; Shannon, J.S.; Lacey, M.J. Org. Mass Spectrom. 1983, 18, 183-192. 
292. Field, F.H. J. Am. Chem. Soc. 1969, 91, 2827-2839.

293. Field, F.H. J. Am. Chem. Soc. 1969, 91, 6334-6341.

294. Field, F.H. In: "Ion Molecule Reactions," Vol. 1; Franklin, J.L., Ed., Butterworths: London, 1972.

295. Meot-Ner (Mautner), M.; Hunter, E.P.; Field, F.H. J. Am. Chem. Soc. 1977, 99, 55765583.

296. Cameron, D.; Cooks, R.G. J. Am. Chem. Soc. 1979, 101, 3162-3168.

297. Kuck, D. Angew. Chem., Int. Ed. Engl. 1984, 23, 508-509.

298. Kuck, D.; Bögge, H. J. Am. Chem. Soc. 1986, 108, 8107-8109.

299. Kuck, D.; Schuster, A. Angew. Chem., Int. Ed. Engl. 1988, 27, 1192-1194.

300. Kuck, D.; Schuster, A.; Ohlhorst, B.; Sinnwell, V.; de Meijere, A. Angew. Chem., Int. Ed. Engl. 1989, 28, 595-597.

301. Kuck, D. In: "Quasicrystals, Networks, and Molecules with Fivefold Symmetry"; Hargittai, I., Ed., VCH Publishers: New York, 1990, Chap. 19, in press.

302. Meot-Ner (Mautner), M.; Hamlet, P.; Hunter, E.P.; Field, F.H. J. Am. Chem. Soc. 1978, 100, 5466-5471.

303. Meot-Ner (Mautner), M. Acc. Chem. Res. 1984, 17, 186-193.

304. Kuck, D.; Fastabend, U., to be published.

305. Adams, N.G.; Smith, D.; Henchman, M.J. Int. J. Mass Spectrom. Ion Phys. 1982, 42, $11-$ 23.

306. Henchman, M.J.; Smith, D.; Adams, N.G. Int. J. Mass Spectrom. Ion Phys. 1982, 42, 2532.

307. Lias, S.G.; Ausloos, P. "Ion-Molecule Reactions, Their Role in Radiation Chemistry", American Chemical Society: Washington, D.C. 1975, Chap. 5.

308. Henchman, M.; Smith, D.; Adams, N.G.; Paulson, J.F.; Herman, Z. Int. J. Mass Spectrom. Ion Proc. 1989, 92, 15-36.

309. Kuck, D.; Ingemann, S.; de Koning, L.J.; Grützmacher, H.-F.; Nibbering, N.M.M. Angew. Chem., Int. Ed. Engl. 1985, 24, 693-695.

310. Wolf, J.F.; Devlin, J.L., III; DeFrees, D.J.; Taft, R.W.; Hehre, W.J. J. Am. Chem. Soc. 1976, $98,5097-5101$.

311. Ausloos, P.; Lias, S.G. J. Am. Chem. Soc. 1977, 99, 4198-4199.

312. Yamamoto, Y.; Takamuku, S.; Sakurai, H. Chem. Lett. 1974, 849-852.

313. Yamamoto, Y.; Takamuku, S.; Sakurai, H. Chem. Lett. 1975, 683-684.

314. Yamamoto, Y.; Takamuku, S.; Sakurai, H .J. Am. Chem. Soc. 1978, 100, 2474-2478.

315. Traynham, J.G. J. Chem. Educ. 1983, 60, 937-941. 